\title{
A Numerical Taxonomic Study of the Genus Shigella
}

\author{
By CHRISTINE E. R. DODD AND DOROTHY JONES* \\ Department of Microbiology, The University, Leicester LEI 7RH, U.K.
}

(Received 26 November 1981; revised 26 February 1982)

One hundred and two strains representing the four species of the genus Shigella and sixty-four strains representing fourteen other genera of the family Enterobacteriaceae were tested for 192 characters based on their morphology, biochemistry and physiology. The data were subjected to a number of numerical analyses. The results (confirmed by the use of overlap statistics) showed that four phenons can be distinguished within the genus Shigella. These correspond with the species $S$. dysenteriae, $S$. flexneri, $S$. boydii and $S$. sonnei.

Of the other bacteria studied the Alkalescens-Dispar group was most closely related to the genus Shigella and the need for this group to be studied further is noted. The importance of using computer-based matrices for the routine identification of strains of Shigella and other enterobacteria is discussed.

Strains of the genus Providencia clustered separately from the shigellae. Three distinct species were evident within this genus: $P$. stuartii, $P$. alcalifaciens and a new Providencia species. The latter can be equated with the 'BG3' group in the DNA-DNA hybridization studies of Brenner et al. (1978).

\section{INTRODUCTION}

The present classification of the genus Shigella (Carpenter, 1974) is based on that first proposed by Ewing (1949) which was later amended and extended by the International Enterobacteriaceae Subcommittee (Report, 1951, 1953, 1954, 1958). Four species, sometimes referred to as subgroups, are recognized within the genus, $S$. dysenteriae (subgroup A), S. flexneri (subgroup B), S. boydii (subgroup C) and S. sonnei (subgroup D) (Edwards \& Ewing, 1972; Carpenter, 1974). The first three species are divided into a number of serotypes. Although each has qualitatively distinct antigens, serological cross reactions do occur between them and also with Escherichia coli strains (Edwards \& Ewing, 1972; Carpenter, 1974).

The four species are distinguished biochemically mainly on the basis of the production of acid from mannitol and lactose and indole production (Carpenter, 1974). However, in practice the distinction is not clear cut and it is frequently difficult to identify new isolates with confidence. In their work on the construction of a computer-based identification matrix for Gram-negative, fermentative rod-shaped bacteria, Bascomb et al. (1973) found that they could not produce a system which would distinguish between reference strains of the species $S$. flexneri, S. boydii and $S$. dysenteriae. In addition, strains of Shigella species were frequently mis-identified as Alkalescens-Dispar strains, and strains of Escherichia coli and of the Alkalescens-Dispar group were mis-identified as shigellae.

Some recent numerical taxonomic studies of representatives of the family Enterobacteriaceae have raised questions about the current phenetic classification of the genus Shigella. Johnson et al. (1975) found that only strains of $S$. sonnei could be distinguished as a distinct taxon; the remaining shigellae clustered as a diffuse group which could not be equated with any particular species. In the study of Véron \& Le Minor (1975), only strains of $S$. dysenteriae formed a distinct taxon. Strains of the other three species fell into two groups, neither of which could be deemed to represent a currently accepted species within the genus Shigella. While in a numerical taxono- 
mic study of the Proteus-Providence group of bacteria (McKell \& Jones, 1976) two strains labelled $S$. dysenteriae clustered in the Providencia alcalifaciens taxon.

On the basis of DNA relatedness, guanine plus cytosine content and genome size, Brenner $e t$ al. (1973) concluded that it was difficult to distinguish between Shigella species and E. coli but that the Proteus-Providence group was distinct from Shigella and E. coli.

Several problems are therefore apparent in the taxonomy of the genus Shigella. Can the four species of the genus Shigella be distinguished on the basis of their biochemical and cultural characteristics: if so, what characters distinguish each species? Can members of the genus Shigella be readily distinguished from strains of $E$. coli and the Alkalescens-Dispar group by biochemical and cultural characters? What is the nature, if any, of the apparent phenetic relationship between the genera Shigella and Providencia? This study was undertaken in an attempt to answer these questions.

\section{METHODS}

Strains. These are listed in Table 1. Most were obtained from culture collections but some fresh isolates were included. Type strains were used wherever possible. At the time this study was begun type strains were not designated for the species S. flexneri, S. boydii or S. sonnei (Carpenter, 1974). To determine the reproducibility of the test system 11 cultures were split and the duplicates treated as separate strains throughout the study. These duplicated cultures are suffixed A and B after the study number.

The names of the bacteria used here are those included in the Approved Lists of Bacterial Names (Skerman $e t$ al., 1980) which now determine the nomenclature of bacteria. Where strains bearing names not included in the List are referred to, they are put in quotation marks.

Strains were stored as broth cultures frozen in glycerol at $-76^{\circ} \mathrm{C}$ on beads (Feltham et al., 1978). Additionally, strains were subcultured at three weekly intervals on blood agar base plates and stored at $4^{\circ} \mathrm{C}$.

Basal media. The bacteria were grown on Blood Agar Base (BAB; Oxoid) or in Nutrient Broth no. 2 (NB2; Oxoid) when a liquid culture was needed. These were the basal media used for many of the tests. When a less rich medium was required, e.g. when cultures were to be used for inoculating carbon source utilization tests, peptone water agar $[1 \%, \mathrm{w} / \mathrm{v}$ Bacteriological peptone (Oxoid) $; 0.5 \%, \mathrm{w} / \mathrm{v} \mathrm{NaCl} ; 0.5 \%, \mathrm{w} / \mathrm{v}$ Oxoid Agar no. 3] was used. In tests where single colonies were required, the swarming of Proteus strains was prevented by the addition of $0 \cdot 18 \%$ $(\mathrm{w} / \mathrm{v})$ sterile chloral hydrate which was added to the sterile molten medium before dispensing. Normally, all tests were inoculated from overnight $\mathrm{BAB}$ cultures. Unless otherwise stated, incubation was at $37^{\circ} \mathrm{C}$ overnight $(18$ to $24 \mathrm{~h}$ ) except for strain D1514 which required $48 \mathrm{~h}$ to produce significant growth.

Colonial morphology. Twenty-four hour cultures on plates of BAB and nutrient agar (NA, Difco) were examined for colonial morphology by eye and under low power magnification $(\times 10)$ on a binocular microscope using transmitted and reflected light. The growth of the strains on BAB and NA was compared and the BAB plates were examined for swarming $\left(37^{\circ} \mathrm{C}\right)$. The ability to swarm was also tested on $\mathrm{BAB}$ at $25^{\circ} \mathrm{C}$.

Cell morphology. Smears of strains grown on BAB and NA were made in saline on slides and Gram stained by the method of Baker (1967). Acetone was used as decolouriser. The slides were examined at $\times 1000$ magnification.

Motility. This was examined at 25 and $37^{\circ} \mathrm{C}$. NB2 solidified with $0.25 \%$ (w/v) agar (Oxoid No. 3) was dispensed in $15 \mathrm{ml}$ amounts into universal bottles containing Craigie tubes (Craigie, 1931). After inoculation of the Craigie tube the bottles were incubated for $3 \mathrm{~d}$ and examined daily for growth in the outer tube. All strains giving a positive result were re-examined for motility by the hanging drop method using 6 and $24 \mathrm{~h} \mathrm{NB} 2$ cultures of the organism. Only those confirmed as motile by this method were scored as positive.

Growth characteristics in broth. Tubes of NB2, preincubated at $37^{\circ} \mathrm{C}$, were lightly inoculated and incubated overnight. The broths were examined for the presence of a ring or pellicle, the presence of a deposit and degree of turbidity.

Growth at different temperatures. Growth was examined at 4,10 and $45^{\circ} \mathrm{C}$. Bacteria were lightly inoculated into tubes of NB2, preincubated at the appropriate temperature. The cultures were examined for growth after overnight incubation at $45^{\circ} \mathrm{C}$, and daily for $21 \mathrm{~d}$ for growth at 4 and $10^{\circ} \mathrm{C}$.

Initiation of growth at different pH values. Growth was tested at $\mathrm{pH} 4,6,8$ and 10. BAB was adjusted to the required $\mathrm{pH}$ before autoclaving and then dispensed into repli dishes (Sterilin). The media were stab inoculated by the multi-inoculation technique (Stevens, 1969) and incubated for $7 \mathrm{~d}$. The plates were examined for growth at 1,2, 3 and $7 \mathrm{~d}$. Day 2 results were used for coding the data.

Initiation of growth at different $\mathrm{NaCl}$ concentrations. Sodium chloride was added to NA to give added concentrations of $0 \%, 0.5 \%, 5.0 \%$, and $10 \%(\mathrm{w} / \mathrm{v}) \mathrm{NaCl}$. The tests were carried out as for the $\mathrm{pH}$ tests. Day 3 results were used for coding the data.

Growth on desoxycholate citrate agar. Desoxycholate citrate agar (Oxoid) was prepared as instructed by the manufacturer. The medium was dispensed into repli dishes and stab inoculated. Plates were incubated and examined daily for $3 \mathrm{~d}$ for the presence of growth and the production of black colonies. 
Table 1. Strains used in study

Species

Shigella

S. boydii serotype 1

$S$. boydii serotype 1

$S$. boydii serotype 2

$S$. boydii serotype 3

$S$. boydii serotype 3

$S$. boydii serotype 4

$S$. boydii serotype 5

S. boydii serotype 6

S. boydii serotype 7

S. boydii serotype 8

S. boydii serotype 9

S. boydii serotype 10

$S$. boydii serotype 10

$S$. boydii serotype 11

S. boydii serotype 12

$S$. boydii serotype 13

$S$. boydii serotype 14

$S$. boydii serotype 15

$S$. boydii serotype 15

S. dysenteriae serotype 1

S. dysenteriae serotype 1

S. dysenteriae serotype 1

$S$. dysenteriae serotype 1

$S$. dysenteriae serotype 2

$S$. dysenteriae serotype 2

S. dysenteriae serotype 2

$S$. dysenteriae serotype 2

S. dysenteriae serotype 2

$S$. dysenteriae serotype 3

$S$. dysenteriae serotype 3

$S$. dysenteriae serotype 4

$S$. dysenteriae serotype 4

$S$. dysenteriae serotype 5

S. dysenteriae serotype 5

$S$. dysenteriae serotype 6

S. dysenteriae serotype 6

S. dysenteriae serotype 7

S. dysenteriae serotype 7

S. dysenteriae serotype 8

$S$. dysenteriae serotype 8

S. dysenteriae serotype 8

$S$. dysenteriae serotype 9

$S$. dysenteriae serotype 10

S. dysenteriae serotype 3873-50

$S$. dysenteriae serotype 2000-53

S. dysenteriae

S. dysenteriae

$S$. dysenteriae

S. flexneri serotype la

$S$. flexneri serotype 1a

$S$. flexneri serotype la

$S$. flexneri serotype $1 \mathrm{~b}$

$S$. flexneri serotype $1 \mathrm{~b}$

$S$. flexneri serotype $2 \mathrm{a}$

$S$. flexneri serotype $2 \mathrm{a}$

$S$. flexneri serotype $2 \mathrm{a}$

$S$. flexneri serotype $2 \mathrm{a}$

$S$. flexneri serotype $2 b$
Source and

original

Study no. designation*

Additional

information

\begin{tabular}{|c|c|}
\hline E12 & PHLL 32395/75 \\
\hline E16 & NCTC 9327 \\
\hline E18 & NCTC 9328 \\
\hline E13 & PHLL 37746/75 \\
\hline E20 & NCTC 9329 \\
\hline E22 & NCTC 9770 \\
\hline E23 & NCTC 9733 \\
\hline E24 & NCTC 9771 \\
\hline E25 & NCTC 9333 \\
\hline E27 & NCTC 9353 \\
\hline E28 & NCTC 9356 \\
\hline E29 & NCTC 9358 \\
\hline E30 & NCTC 9784 \\
\hline E31 & NCTC 9360 \\
\hline E32 & NCTC 9772 \\
\hline E33 & NCTC 9361 \\
\hline E34 & NCTC 9766 \\
\hline $\mathrm{E} 35 \mathrm{~A} / \mathrm{B}$ & NCTC 8590 \\
\hline E36 & NCTC 9365 \\
\hline E37 & NCTC 4837 \\
\hline E38 & NCTC 6781 \\
\hline E39 & Sakazaki 4379-60 \\
\hline $\mathrm{E} 40$ & NCTC 8571 \\
\hline E14 & PHLL 36595/75 \\
\hline E41 & NCTC 2966 \\
\hline E42 & NCTC 8218 \\
\hline E43 & NCTC 9718 \\
\hline E44 & NCTC 9952 \\
\hline E45 & NCTC 9720 \\
\hline E46 & NCTC 9953 \\
\hline E47 & NCTC 9760 \\
\hline E48 & NCTC 9954 \\
\hline E49 & NCTC 9761 \\
\hline E50 & NCTC 9955 \\
\hline $\mathrm{E} 51 \mathrm{~A} / \mathrm{B} / \mathrm{BX}$ & NCTC 9762 \\
\hline E52 & NCTC 9956 \\
\hline E53 & NCTC 9763 \\
\hline E54 & NCTC 9957 \\
\hline E55 & NCTC 8599 \\
\hline E56 & NCTC 9346 \\
\hline E109 & Strain 17 \\
\hline E57 & NCTC 9348 \\
\hline E58 & NCTC 9351 \\
\hline E59 & NCTC 9349 \\
\hline E60 & NCTC 9352 \\
\hline E61 & ATCC $11456 a$ \\
\hline E62 & ATCC $11456 \mathrm{~b}$ \\
\hline E63 & ATCC 23351 \\
\hline E64 & NCTC 3 \\
\hline E65 & NCTC 8192 \\
\hline $\mathrm{E} 66 \mathrm{~A} / \mathrm{B}$ & NCTC 9950 \\
\hline $\mathrm{E} 9 \mathrm{~A} / \mathrm{B}$ & PHLL 33272/75 \\
\hline E67 & NCTC 5 \\
\hline E10 & PHLL $23364 / 7$ \\
\hline E69 & NCTC 1 \\
\hline E70 & NCTC 8519 \\
\hline E72 & ATCC 25875 \\
\hline & \\
\hline
\end{tabular}

Mannitol negative

Mannitol negative

Type strain

(Johnson et al. 1975)

Rough strain
(Véron \& Le Minor, 1975)

Provisional serotype

Provisional serotype

Indicator strain for lysogenic Sd 11456b Lysogenic; carries Phage P2 Phage host 
Species

S. flexneri serotype $2 b$

$S$. flexneri serotype 3

$S$. flexneri serotype 3a

$S$. flexneri serotype 3a

$S$. flexneri serotype 4

$S$. flexneri serotype $4 \mathrm{a}$

$S$. flexneri serotype $4 \mathrm{a}$

$S$. flexneri serotype $4 \mathrm{~b}$

$S$. flexneri serotype $4 \mathrm{~b}$

$S$. flexneri serotype 5

$S$. flexneri serotype 5a

$S$. flexneri serotype 5a

$S$. flexneri serotype $5 \mathrm{~b}$

$S$. flexneri serotype 6

S. flexneri serotype 6

S. flexneri serotype 6

S. flexneri serotype 6

S. flexneri serotype 6

S. flexneri serotype 6

S. flexneri serotype $\mathbf{X}$

$S$. flexneri serotype $\mathrm{Y}$

$S$. flexneri serotype $\mathrm{Y}$

S. flexneri

S. flexneri

S. sonnei

S. sonnei

S. sonnei

S. sonnel

S. sonnei

S. sonnei

S. sonnei

S. sonnel

S. sonnei

S. sonnei

S. sonnei

S. sonnei

S. sonnei

S. sonnei

S. sonnei

Shigella $\mathrm{sp.}$

Shigella sp.

Shigella $\mathrm{sp}$.

Shigella sp.

Shigella sp.

Citrobacter

C. freundii

C. koseri

Edwardsiella

E. tarda

Enterobacter

E. aerogenes

E. cloacae

E. cloacae

'E. liquefaciens'

'E. liquefaciens'
Table 1.-(continued)

Source and original

Study no. designation ${ }^{*}$

E75 NCTC 8518

E76 ATCC 11836

E77 NCTC 9724

E78 NCTC 9989

E79 ATCC 9748

E80 NCTC 8296

E81 NCTC 7885

E83 NCTC 8336

E84 NCTC 9726

E85A/B ATCC 9204

E11 PHLL

E86 NCTC 8523

E87 NCTC 9727

E88 NCTC 9729

E89 NCTC 4720

E90 NCTC 9780

E91 NCTC 9781

E92 NCTC 8525

E93 NCTC 8526

E94 NCTC 9769

E95A/B NCTC 6

E96 NCTC 9730

E97 ATCC 12661

E110 PHLL (Adelaide)

E1 PHLL 8471/75

E2 PHLL $15805 / 75$

E3 PHLL 4406/75

E4 PHLL 7622/75

E5 PHLL 41703/75

E6 PHLL 42312/75

E7 PHLL 42314/75

E8 PHLL 44783/75

E98 NCTC 9774

E99 NCTC 8220

E100 NCTC 8574

E101A/B NCTC 8575

E102 NCTC 8586

E103 NCTC 9992

E104 NCTC 10352

E105 NCTC 2670

E106 NCTC 8589

E107 NCTC 10351

E108 NCTC 10361

E111 PHLL

K9 NCTC 9750

E122 NCTC 10786

K88 NCTC 10396

K93 NCTC 10006

E132 'Bact-chek' strain

K14 NCTC 10005

K16 NCTC 10422

K17 NCTC 10423
Additional

information

Mannitol negative

Manchester variety

Newcastle variety; mannitol negative

Newcastle variety:

mannitol negative; anaerogenic

Boyd 88 variety:

dulcitol positive; anaerogenic

Boyd 88 variety:

dulcitol negative; anaerogenic

Serologically $S$. flexneri 2

Phage host

Standard sulphonamide-

sensitive strain

Sulphonamide-resistant strain

Mannitol negative

Xylose positive

Salicin positive

Indole positive: serotype CDC 147

Indole negative: serotype CDC 147

Serotype CDC 147

Type strain

Type strain

ATCC 13047 derivative

Type strain 
Table 1.-(continued)

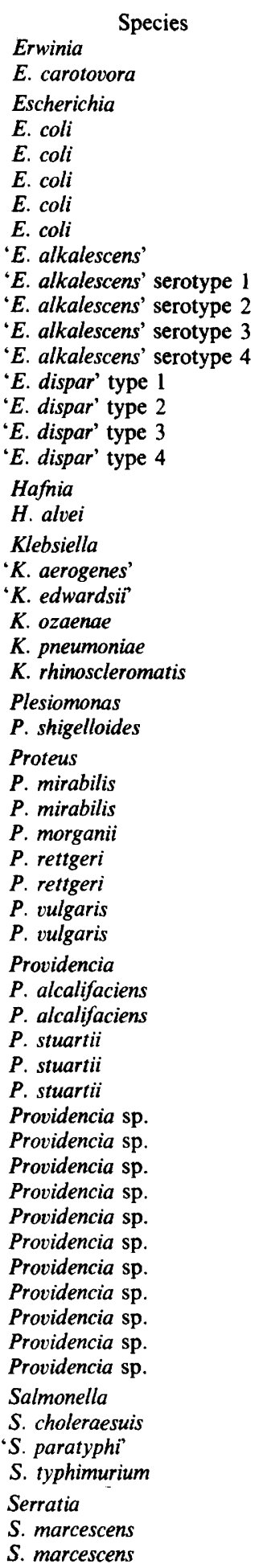

Source and

original

Study no. designation*

Additional

information

D1253 NCPPB 312

$\begin{array}{cll}\text { K1 } & \text { NCTC 9001 } & \text { Type strain } \\ \text { P83A/B } & \text { NCTC 86 } & \\ \text { P103 } & \text { S 149 } & \text { (McKell, 1977) } \\ \text { P104 } & \text { S 274 } & \text { (McKell, 1977) } \\ \text { E131 } & \text { NCTC 9704 } & \text { O type 112 }\end{array}$

$\mathrm{E} 15+\mathrm{K} 11$ NCTC 1601

E127 NCTC 7925

E128 NCTC 7926

E129 NCTC 7927

E130 NCTC 7928

E123 NCTC 7921

E124 NCTC 7922

E125 NCTC 7923

E126 NCTC 7924

K63 NCTC 8105

K38 NCTC 8172

K35 NCTC 5054

K37A/B NCTC 5050

K32 NCTC 9633

K34 NCTC 5046

Type strain

Type strain

Type strain

E113 NCTC 10363

P2 NCTC 3177

P5 NCTC 60

P11 NCTC 235

P18 NCTC 7475

P28 NCTC 10377

P6 NCTC 10376

P7 NCTC 4175

Lactose positive

Type strain

P77 NCTC 10286

E119 ATCC 25828

P78 NCTC 10318

E120 ATCC 25825

E121A/B ATCC 25826

E114 NCTC 8055

E115 NCTC 8057

E116 NCTC 6932

E117 NCTC 6934

E118 NCTC 6344

P22 NCTC 8056

P23 NCTC 6345

P24 NCTC 8113

P32 NCTC 2481

P75 NCTC 6933

P76 NCTC 10378

$\begin{array}{ll}\text { K49 } & \text { NCTC } 5735 \\ \text { K43 } & \text { NCTC } 8002 \\ \text { K46 } & \text { NCTC } 74\end{array}$

Type strain

Type strain

K18A/B NCTC 1377

K19 NCTC 10211

Type strain

Type strain 


\section{Table 1.-(continued)}

\begin{tabular}{|c|c|c|c|}
\hline Species & Study no. & $\begin{array}{l}\text { Source and } \\
\text { original } \\
\text { designation* }\end{array}$ & $\begin{array}{l}\text { Additional } \\
\text { information }\end{array}$ \\
\hline $\begin{array}{l}\text { Vibrio } \\
\text { V. cholerae }\end{array}$ & D1865 & PHLL & Biotype El Tor; Ogawa serotype \\
\hline $\begin{array}{l}\text { Yersinia } \\
\text { Y. enterocolitica } \\
\text { Y. pestis } \\
\text { Y. pseudotuberculosis }\end{array}$ & $\begin{array}{l}\text { D1655 } \\
\text { D1514 } \\
\text { D1516 }\end{array}$ & $\begin{array}{l}\text { Mollaret } 88 \\
\text { NCTC } 5923 \\
\text { NCTC } 8315\end{array}$ & Avirulent working type \\
\hline 'Enterobacterium Sachs A12' & E112 & S 139 & (Howie \& Old, 1976) \\
\hline
\end{tabular}

Growth on selenite agar. Selenite broth base $(19 \mathrm{~g}$; Oxoid) was suspended in distilled water $(800 \mathrm{ml})$ in which sodium biselenite ( $4 \mathrm{~g}$; Oxoid) was dissolved. The solution was sterilized in a boiling water bath for $10 \mathrm{~min}$, then molten agar [ $200 \mathrm{ml}$ of $5 \%(\mathrm{w} / \mathrm{v})$ solution, Oxoid agar No. 3] was added. Repli dishes containing the medium were stab inoculated by the multi-inoculation technique, incubated and examined daily for $3 \mathrm{~d}$.

Growth on potassium cyanide agar. The medium of Cowan $(1974 b)$ was used except that agar $(1 \%$, w/v Oxoid No. 3) was added to the medium before sterilizing. The $\mathrm{KCN}$ agar was dispensed into repli dishes, stab inoculated, then incubated and examined daily for $3 \mathrm{~d}$.

Amino acid decarboxylases. The presence of decarboxylases for four amino acids was tested: L-arginine, Lglutamine, L-lysine and L-ornithine. Method 2 of Cowan (1974b) was used with Decarboxylase Medium Base (Difco) as the basal medium.

Arginine decarboxylase. This was tested by Method 1- of Cowan (1974b).

Urease. Urease agar ( 100 tablets; Oxoid) was dissolved in water $(950 \mathrm{ml})$ and the medium autoclaved at $121{ }^{\circ} \mathrm{C}$ for $15 \mathrm{~min}$. Sterile urea [ $50 \mathrm{ml}$ of $40 \%(\mathrm{w} / \mathrm{v})$ solution; Oxoid] was added after cooling. The medium was dispensed in $3.5 \mathrm{ml}$ amounts into test tubes and slanted. The slants were streaked heavily from overnight cultures and incubated for $5 \mathrm{~d}$. Readings were taken at $4 \mathrm{~h}$ and then daily. All tests were read against a urease-negative $E$. coli control.

Catalase. Colonies of an overnight BAB culture were flooded with $20 \mathrm{vol} \mathrm{H}_{2} \mathrm{O}_{2}$ and observed for the production of effervescence for up to $1 \mathrm{~min}$.

Oxidase. Growth from a fresh BAB culture was rubbed on to Whatman no. 1 filter paper previously soaked in oxidase reagent (Cowan, 1974b; solution 1) and observed for the development of a dark purple colour for up to $10 \mathrm{~s}$ (Kovacs, 1956).

Phenylalanine deaminase. The medium of Edwards \& Ewing (1972) was used and tested by Method 2 of Cowan (1974b).

ONPG test. This was carried out by the method described in Cowan (1974b).

Phosphatase. This was carried out using Method 1 of Cowan (1974b), except that BAB replaced NA as the basal medium.

DNAase. The method was based on that of Smith et al. (1969). Plates of DNAase test agar with methyl green (Difco) were streaked for single colonies and incubated for $2 \mathrm{~d}$. Plates were examined at 24 and $48 \mathrm{~h}$ for the clearing of the green colour around the growth.

Gelatin hydrolysis. Tubes of Nutrient gelatin (Oxoid) were stab inoculated and examined after 5 and $14 \mathrm{~d}$ incubation. Tubes were refrigerated at $4^{\circ} \mathrm{C}$ for $2 \mathrm{~h}$ before reading.

Tributyrin hydrolysis. Plates of tributyrin agar (Oxoid), streaked for single colonies and incubated for $5 \mathrm{~d}$ were examined daily for zones of clearing around the colonies and on day 5 some bacterial growth was removed and the underlying agar examined for clearing.

Casein hydrolysis. The medium described by Cowan (1974b) was used except that BAB replaced NA. The test was carried out as for tributyrin hydrolysis.

Eijkman test. Tubes of MacConkey Broth (Oxoid) containing Durham tubes were inoculated and incubated at $44^{\circ} \mathrm{C}$ for $48 \mathrm{~h}$. Tubes were examined for turbidity and the production of acid and gas.

Oxidation-fermentation of glucose. Tubes of O.F. basal medium (Difco) were inoculated and incubated according to the method of Hugh \& Liefson (1953).

Indole production. Indole production was tested in tubes of Tryptone water (Oxoid) according to Method 2 of Cowan (1974b). The production of indole was examined after incubation for $48 \mathrm{~h}$ at 37 and $44^{\circ} \mathrm{C}$.

Methyl red and Voges Proskauer tests. MR/VP medium (Oxoid) was dispensed in $1.5 \mathrm{ml}$ amounts in bijou bottles and sterilized. Inoculated bottles were incubated at $37^{\circ} \mathrm{C}$ for $2 \mathrm{~d}$ and then tested. For the MR tests 10 drops of 
methyl red solution (Cowan, 1974b) were added. The VP test was carried out according to Method 1 of Cowan $(1974 b)$.

Hydrogen sulphide production. Two sulphide sources were used: cysteine and thiosulphate. The following medium containing $\left(\mathrm{g} \mathrm{l}^{-1}\right)$ : peptone (Oxoid) 15; proteose peptone (Oxoid) 5 ; brown ferric ammonium citrate (Fisons) 0.5; dipotassium hydrogen phosphate (BDH) 1 ; agar (Oxoid) 15 ; either sodium thiosulphate (BDH) 0.08 or cysteine hydrochloride (BDH) 0.5 , was dispensed in $4 \mathrm{ml}$ amounts into large test tubes which were then slanted. The media were inoculated by stabbing the butt and streaking the slant. Tubes were incubated for $7 \mathrm{~d}$ and examined daily for blackening of the medium.

Gas production from carbohydrates and production of ammonia from peptone. Carbohydrates tested were : adonitol, dulcitol, glycerol, glucose, inositol, maltose, mannitol and starch. To the following basal medium containing $\left(\mathrm{g} \mathrm{l}^{-1}\right)$ : Bacteriological peptone (Oxoid) 10; sodium chloride (Fisons) 5; bromothymol blue 0.04, was added the appropriate carbohydrate as a filter-sterilized solution to give a final concentration of $1 \%(\mathrm{w} / \mathrm{v})$. In the case of the starch-containing medium the carbohydrate was added to the basal medium before sterilizing and autoclaved at $115^{\circ} \mathrm{C}$ for $10 \mathrm{~min}$. The media were dispensed $(4 \mathrm{ml})$ into $4 \times 0.5$ inch tubes containing Durham tubes. Before inoculation these were steamed for $30 \mathrm{~min}$ to remove all air from the Durham tubes. The inoculated tubes were examined daily for $3 \mathrm{~d}$ and then at 7 and $14 \mathrm{~d}$ for the production of gas. The production of ammonia from peptone was tested in tubes of the basal medium containing no carbohydrate. Ammonia production was measured by the change of the indicator colour from green to blue.

Reduction of nitrate. This was carried out by Method 1 of Cowan (1974b) with NB2 as the basal medium.

Reduction of nitrite. The method described in Cowan (1974b) was used with NB2 as the broth medium.

Carbon source utilization. The basal medium of Véron (1975) was supplemented with yeast extract (Difco) to a final concentration of $0.005 \%(\mathrm{w} / \mathrm{v})$. The carbon source $(5 \mathrm{~g})$ was added to the basal medium before autoclaving except for the following which were added as filter-sterilized solutions to the sterile medium: fructose, cellobiose, lactose, galactose, raffinose and ethanol.

The media were dispensed in $2.5 \mathrm{ml}$ amounts into repli-dishes (Sterilin) and the dishes dried to remove surface water. Overnight cultures on peptone agar were suspended in sterile $\mathrm{NaCl}(0 \cdot 9 \%, \mathrm{w} / \mathrm{v})$ to give approximately $10^{5}$ organisms per $\mathrm{ml}$. The diluted cultures were used to inoculate the carbon source media. Growth was assessed by eye after 1, 2, 3 and $7 \mathrm{~d}$ incubation. In all cases a control dish with no added carbon source was set up and used as a comparison when assessing the growth.

Acid from carbohydrates. This was tested in peptone water agar [peptone (Oxoid), $1 \%(\mathrm{w} / \mathrm{v}) ; \mathrm{NaCl}, 0.5 \%(\mathrm{w} / \mathrm{v})$; agar (Oxoid no. 3), $0.5 \%(w / v)]$, containing bromothymol blue indicator at a final concentration $0.004 \%(w / v)$. Filter-sterilized carbohydrates (with certain exceptions) were added to the sterilized basal medium to give a final concentration of $1 \%(\mathrm{w} / \mathrm{v})$. The exceptions were dextrin, starch, aesculin, mucate and glycogen. These substances did not form a solution which was readily filter-sterilized and were therefore added to the medium before autoclaving. The media were dispensed into repli-dishes (Sterilin), inoculated with overnight cultures, incubated and read daily for $8 \mathrm{~d}$, then every $2 \mathrm{~d}$ up to $14 \mathrm{~d}$. Acid production on days $1-6$ was scored as 'early', on days $7-14$ as 'late'.

Antibiotic sensitivities. BAB plates were flooded with overnight broth cultures and the excess carefully removed. Multodisks (Oxoid) containing appropriate antibiotics were then placed on the plates. Sensitivities were recorded after 1 and $2 \mathrm{~d}$.

Dye sensitivity. The medium and method of Serény (1967) were used. Only one dye, basic fucshin, was tested. Not only did we not obtain the species discrimination noted by Serény (1967), we also found the test to be $<15 \%$ reproducible. The results of this test were therefore not included in the study.

Coding of characters. The data were coded as characters with either two- or three-states. The two-state characters were coded as positive and negative and scored as 1 and 0 , respectively. The three-state characters were coded as strongly positive, weakly positive and negative and were scored as 2,1 and 0 , respectively.

Before coding the results were scrutinized for tests which gave identical results for all the strains studied. Eight tests were not scored for this reason; these were: Gram reaction (negative); shiny colonies on NA; glutamine decarboxylase (negative); acid produced early from glucose (strongly positive) and L-xylose (negative); acid produced late from erythritol and mucate (negative); utilization of formate (negative).

Certain other test results were not included in the coded data because of their lack of reproducibility. These were colonial morphological characters (opacity, elevation, edge, rough or smooth surface and ease with which the colony could be emulsified in saline whether grown on BAB or on NA) and sensitivity to basic fucshin.

Computation. All computing was done on the University of Nottingham ICL 1900 computer, except for the dendrograms which were produced on the University of Leicester CDC CYBER 72 using the TAXPAK program written by M. J. Sackin. Gower's (1971) similarity coefficient $\left(S_{G}\right)$ was computed and clustered by unweighted pair group average linkage (UPGMA) and single linkage methods (Sneath \& Sokal, 1973).

The data were converted to two-state character data by combining 'strongly positive' and 'weakly positive' in the three-state characters, into a single 'positive' state scored as 1 and leaving the two-state characters unchanged. The simple matching coefficient $\left(S_{S M}\right)$ and the pattern difference coefficient $\left(D_{P}\right)$ (Sneath \& Sokal, 1973) were 
then computed on the converted data, and both similarity matrices were clustered by the same two methods. For every clustering the cophenetic correlation was computed between the dendrogram and the similarity matrix from which it was derived.

The IGROUPS (Integer groups) program printed character value statistics on specified groups of OTUs chosen from the sorted matrix. Overlap statistics were computed by means of the OVCLUST program (Sneath, 1979). The program was run on data for every pair of clusters using the intercentroid distance $(D)$ between each pair of clusters and the standard deviation $\left(s_{q}\right)$ of the $q$-distributions of each cluster of the pair. The $D$ and $s_{q}$ values were obtained from a revised IGROUPS program. The chosen overlap used was $5 \%$.

\section{RESULTS}

\section{Reproducibility}

The similarity between duplicate strains varied from $92 \cdot 4 \% \mathrm{~S}$ to $98 \cdot 4 \% \mathrm{~S}$, the average similarity between the duplicates being about $95 \%$. This indicates an estimated average error in testing of $2.46 \%$. Test reproducibility was studied by repeating 28 tests (resulting in 51 characters) for all strains and comparing the two sets of data. The reproducibility obtained varied from $100 \%$ to $62 \%$. Sneath \& Johnson (1972) have suggested that tests showing errors in reproducibility of 10 $15 \%$ are acceptable. Fourteen test characters fell outside the $90 \%$ reproducibility level and eight of these outside a level of $85 \%$ reproducibility.

The best reproducibilities were for antibiotic sensitivities ( $95-100 \%$ reproducible), and many of the biochemical tests such as gelatin hydrolysis, catalase, indole production, fell within this range of reproducibility also. The production of acid from carbohydrates showed good reproducibility although the range here was greater $(99.4 \%-88.7 \%)$, the poorer reproducibility being for the late production of acid. Results for the utilization of carbon sources were reproducible within the range of $85-95 \%$, although one carbon source (2-oxoglutarate) showed reproducibility of $72 \%$.

Characters based on colonial morphology showed the poorest reproducibility. Although a few gave high scores of $99 \%$ (red colony colour, shiny surface, presence of striations), most were below $85 \%$ reproducible and two (flat colony, entire colony edge) were less than $65 \%$ reproducible. The reading of colonial morphology characters is subjective and only where the categories were well defined was there good reproducibility. Where the dividing line between categories was less specific (e.g. between a flat and a low convex colony) and more subjective, reproducibility was poor. This was a particular problem in this study as most of the bacteria under investigation were all very similar in their colony morphology and only small differences in appearance were being determined. Because of their poor reproducibility most of the colonial morphology data (see Coding of characters in Methods) were excluded from the coded data matrix.

\section{Cluster analysis}

The results of the different computations gave broadly similar groupings. The classification which resulted from UPGMA clustering on the Gower coefficient (Figs 1 and 2) will be described in detail. Reference will be made to the pattern coefficient/UPGMA analysis which makes allowances for differences in growth rates and other factors which can distort similarity values (Sneath, 1968).

In the dendrogram derived from UPGMA clustering on the Gower coefficient (Figs 1 and 2) all the strains grouped into six Areas at a similarity level of $75 \%$. Area 1 contains all the strains received as Shigella spp., strains of the Alkalescens-Dispar group, Providencia spp., two strains of Proteus rettgeri and single strains received as 'enterobacterium Sachs' type A12', E. coli, Pleisomonas shigelloides, Edwardsiella tarda and Vibrio cholera. Area II contains strains received as members of the genera Citrobacter, Escherichia, Salmonella and of the species Enterobacter liquefaciens, Hafnia alvei and Erwinia carotovora. Area III contains all the Proteus species studied with the exception of Prot. rettgeri. Area IV contains mainly members of the genera Klebsiella and Enterobacter. Area V contains other members of the genus Klebsiella. Area VI contains representatives of the genus Serratia. At a similarity level of approximately $80 \%$ all but four of the strains clustered into 14 phenons (Figs 1 and 2). 
In the dendrogram derived from the UPGMA clustering based on the pattern coefficient only five Areas were evident at a similarity level of $75 \%$. With the exception of Ent. liquefaciens (strains K16, K17) and Erw. carotovora (strain D1253) all the strains in Area II (Figs 1 and 2) moved into Area 1. The only other major change in classifications based on the different coefficients was the position of phenons D and E which moved out of Area 1 (Figs 1 and 2) and grouped with phenon $\mathrm{K}$ to form Area III. The strain composition of the phenons was almost identical in both computations. One strain in phenon E (Prot. rettgeri, P28) grouped with phenon $\mathrm{O}$ in Area VI.

\section{Description of the phenons}

Phenon A $(82.5 \% \mathrm{~S})$ contains all the strains received as members of the genus Shigella, seven of the eight Alkalescens-Dispar strains, one E. coli strain and one 'enterobacterium Sachs' type A12'. Eight subphenons (A1-A8) are evident within the cluster.

Subphenon A1 $(89.5 \% \mathrm{~S})$ contains all the $S$. sonnei strains (16) studied and one strain of ' $E$. dispar'. The subphenon corresponds to the species $S$. sonnei. The eight strains of $S$. sonnei which were received as new isolates ('S. sonnei clinical', Fig. 1) show a high degree of relatedness $(94.5 \% \mathrm{~S})$ to each other. However, no single character or set of characters was unique to this 'clinical' group of $S$. sonnei, although certain of them did show resistance to a higher proportion of the antibiotics tested.

The 'E. dispar' strain (E126) which clusters with the $S$. sonnei strains is quite typical of the subphenon in its biochemical reactions. It does not ferment xylose, dulcitol, sorbitol or salicin; rhamnose and maltose are fermented early; lactose and sucrose are fermented late; lysine and ornithine are not decarboxylated. Wheeler identified this strain as $S$. sonnei (Catalogue of the National Collection of Type Cultures, 1972) and from the clustering of E126 here it appears that this is the correct classification of this strain. The serological relationship of this strain to $S$. sonnei is not known to us.

Subphenon A2 $(87.5 \%$ S) contains three Shigella strains (E106-E108) and one ' $E$. dispar' strain. The three Shigella strains are closely related at $94.5 \% \mathrm{~S}$. These three strains share the same serotype (147 or 145/46 Carpenter, Ewing et al., 1958) which is antigenically identical to $S$. dysenteriae serotype 3, and to E. coli $\mathrm{O}$ group 124. Many authors (Manolov, 1959; Manolov \& Trifanova, 1962; Tekelieva, 1975) would include such strains as part of the genus Shigella whilst others (Rowe et al., 1977) uphold the present classification of such strains as E. coli variants. The serotype 147 strains studied by us differed from $E$. coli in that they did not decarboxylate lysine, nor ferment salicin nor produce acid early from lactose. However, they did ferment sorbitol (unusual amongst shigellae) and utilize sodium acetate. This latter characteristic alone would lead to their exclusion from the genus Shigella by the criteria of Edwards \& Ewing (1972).

Subphenon A3 $(89.5 \% \mathrm{~S})$ contains 34 strains. All but one of the $S$. flexneri strains of serotypes 1-5 (31 strains) cluster here together with one strain (E28) received as $S$. boydii and two received as Shigella species. This subphenon corresponds to the species $S$. flexneri. There is some evidence of subgrouping within the cluster but this does not seem to be strongly correlated with serotype (Fig. 1).

The $S$. boydii strain (E28) clustering in subphenon A3 is of serotype 9. Strains of this serotype often show features not characteristic of the species $S$. boydii, viz. late lactose fermentation and rhamnose fermentation. However, strain E28 did not show these characteristics. Serological cross-reactions between $S$. boydii serotype 9 and certain serotypes of $S$. flexneri are known (Edwards \& Ewing, 1972).

Shigella strain E105 was known previously as Gettings' bacillus (Andrewes \& Inman, 1919). These authors stated that the strain was typical of the 'S. paradysenteriae' group but was not serologically related to the five serotypes of Andrewes \& Inman (1919). In the Catalogue of the National Collection of Type Cultures (1972) this strain is listed as a Shigella sp. with a side listing as $S$.dysenteriae (though no reason is given for this side listing). On the evidence produced in our study, strain E105 would appear to be part of the species $S$. flexneri. Its serological reactions are not known to us, thus we do not know if it is serologically related to the 'flexneri' group.

Subphenon A4 $(89 \% \mathrm{~S})$ contains 27 strains. These comprise all but five of the $S$. boydii strains studied, eight strains of $S$. dysenteriae, three strains of $S$. flexneri serotype 6 and a strain of 


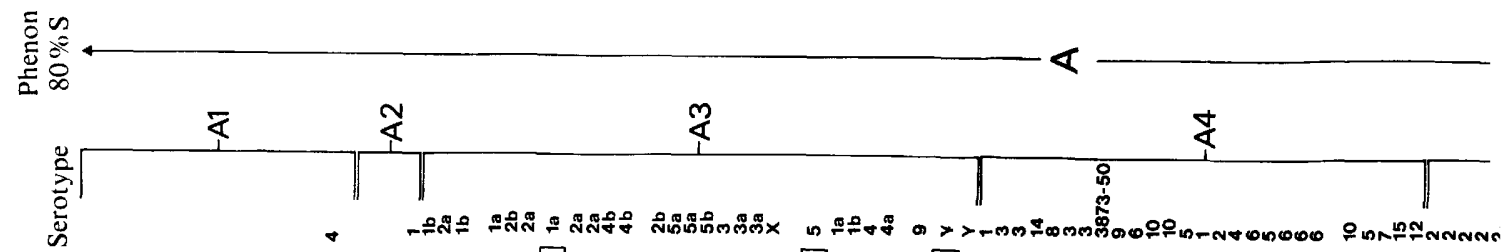

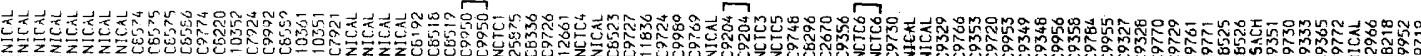

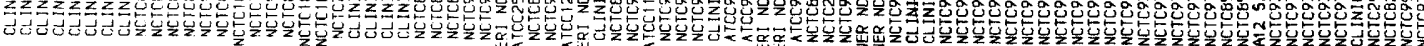

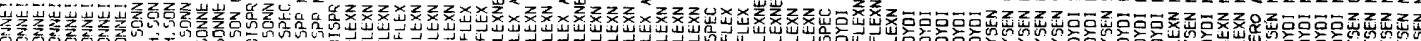

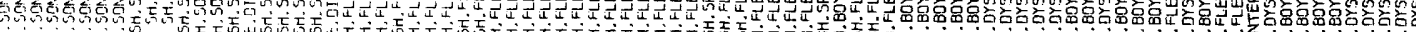

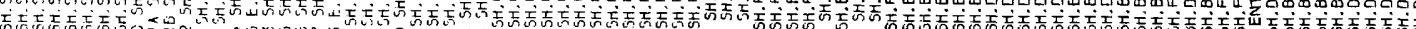

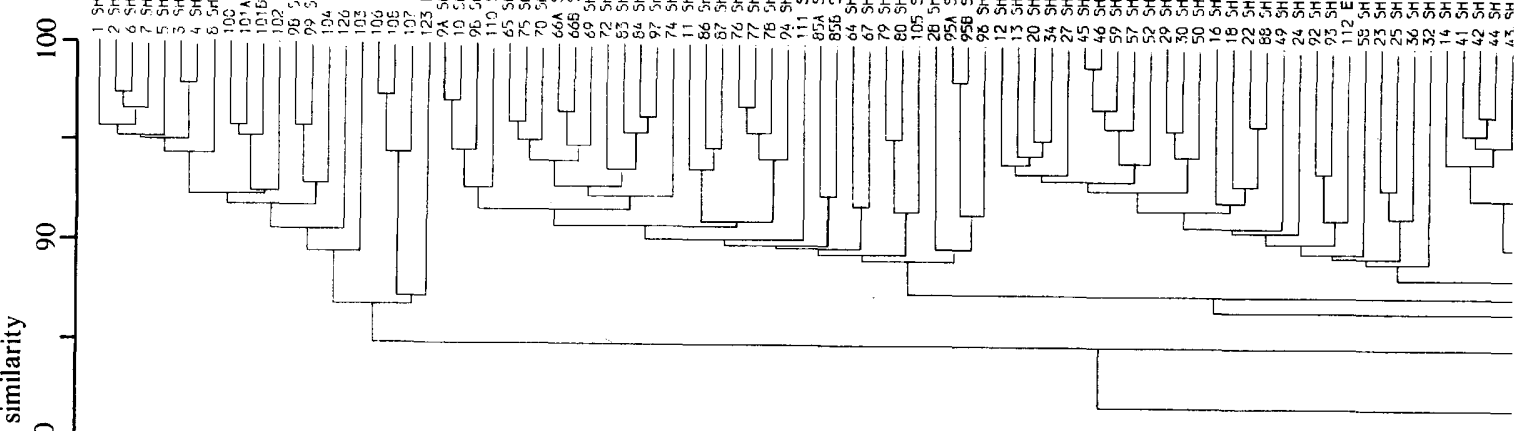
$\infty$

这

2

P 8 
영 \&

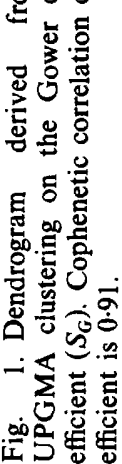

$\bar{\alpha}$

$\frac{\bar{x}}{\frac{4}{4}}$

$\frac{\mathbb{\alpha}}{\alpha}$

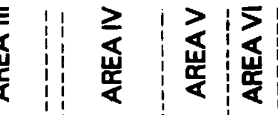

nu

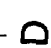

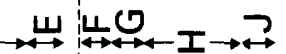

$\underline{\sim}$
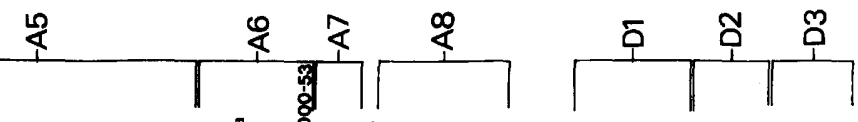

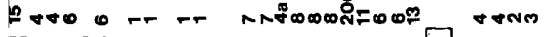

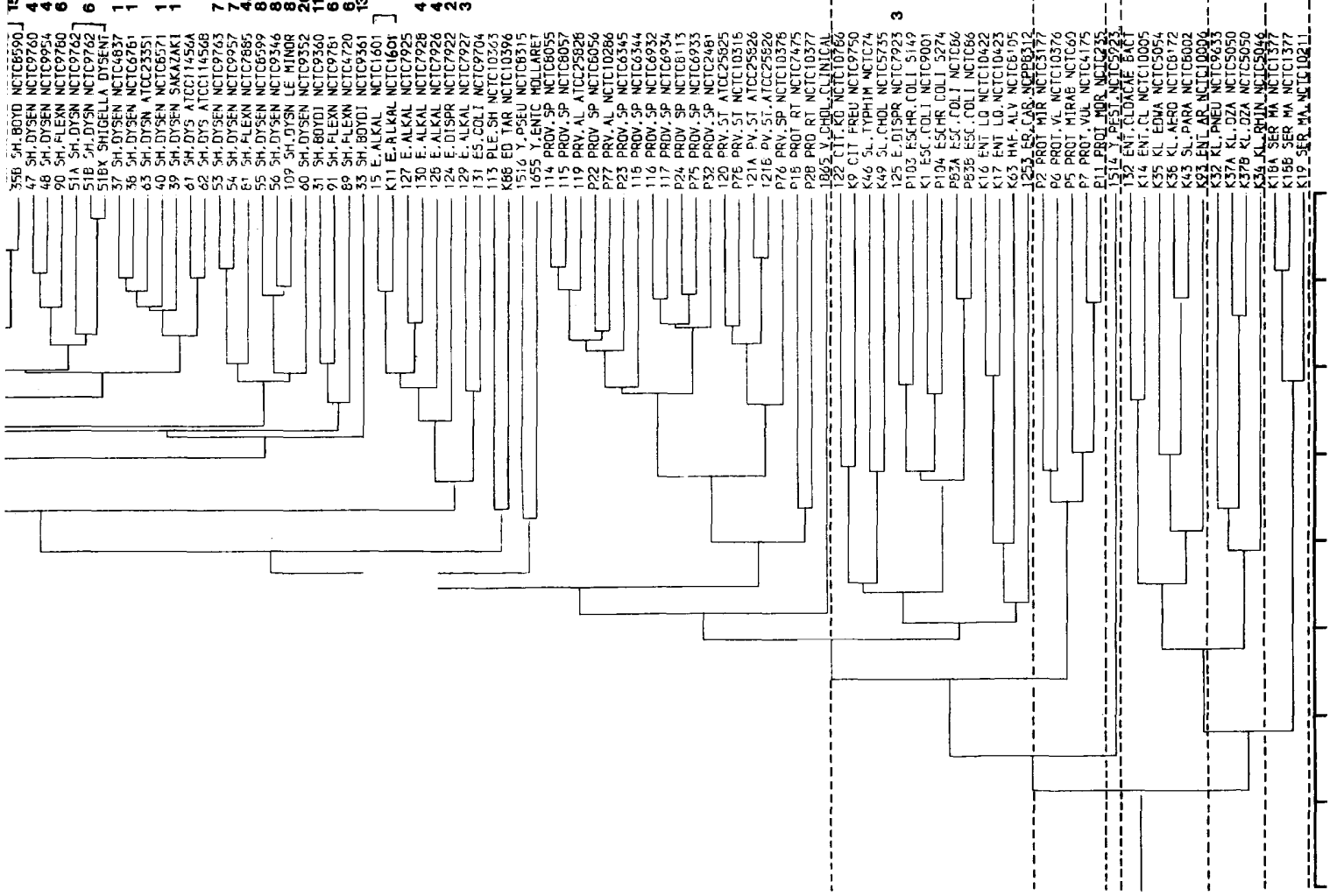




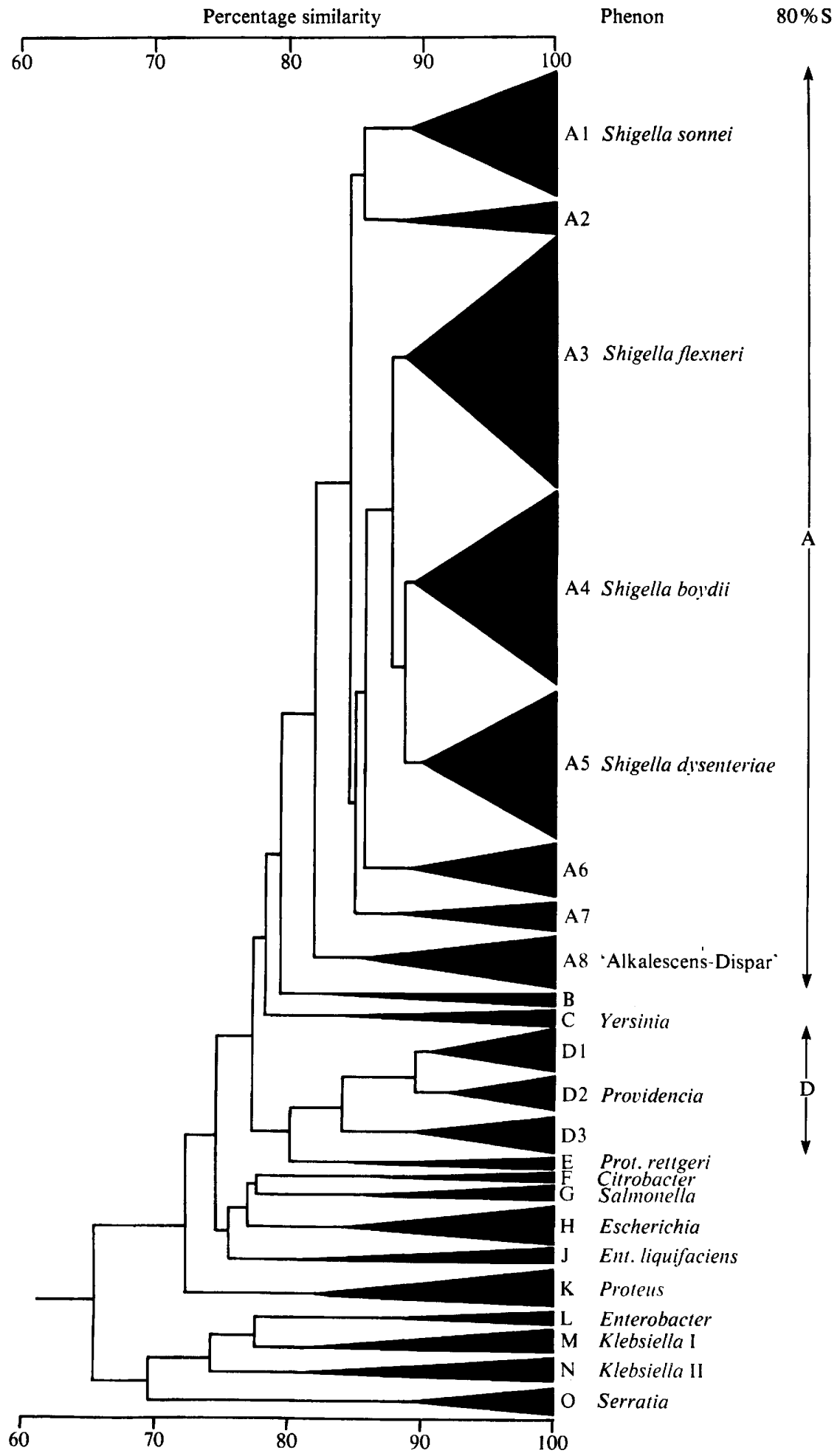

Fig. 2. Simplified dendrogram showing the main clusters in Fig. 1. 
'enterobacterium Sachs' type A12'. The subphenon may be equated with the species $S$. boydii.

Too few strains of $S$. boydii are present to determine if there is any relation between the formation of subgroups and serotypes. The two $S$. boydii serotype 10 strains (E29 and E30) do cluster together, as do the two $S$. boydii serotype 3 strains (E20 and E34); however, the $S$. boydii serotype 15 strains (E35A/B and E36) do not show a close association.

The $S$.dysenteriae strains clustering with $S$. boydii are of serotypes $3,5,6,9,10$ and provisional serotype 3873-50. Except for the strain of serotype 10, these strains show a very high similarity on the basis of pattern. $S$. dysenteriae serotype 3 is unusual in being the only $S$. dysenteriae serotype to frequently produce acid from mannitol; however, neither of the $S$. dysenteriae serotype 3 strains studied was mannitol positive. Shigella dysenteriae serotype 5 strains are unusual in fermenting dulcitol; a character generally found amongst shigellae only in $S$. boydii strains of certain serotypes and in some $S$. flexneri serotype 6 strains. Serological cross-reactions are known between $S$. dysenteriae serotype 5 and serotype 4 of $S$. boydii (Edwards \& Ewing, 1972). The strains of $S$. dysenteriae serotypes 9,10 and provisional serotype 3873-50 all fermented D-xylose, a characteristic found restricted primarily to the strains of subphenon A4 amongst the shigellae studied here. Serological cross-reactions are also known between $S$. boydii serotype 1 and $S$. dysenteriae serotype 10 (Edwards \& Ewing, 1972).

The clustering of the 'enterobacterium Sachs' A12' type with the $S$. boydii cluster supports the suggestion of various workers (Carpenter, 1961; Szturm-Rubinsten et al., 1962; Howie \& Old, 1976; Regina et al., 1981) that such strains are aerogenic, mannitol negative variants of $S$. boydii serotype 14 with which 'Sachs' A12' strains are antigenically identical.

The three S. flexneri serotype 6 strains clustering in subphenon A4 are of the Boyd 88 variety (which produce only acid from glucose and mannitol). Two (strains E88 and E92) ferment dulcitol and the other strain (E93) does not. Only two of these $S$. flexneri strains (E92, E93) cluster together; strain E88 shows the closest relationship to $S$. boydii serotype 4 (strain E22).

Subphenon A5 $(90 \% \mathrm{~S})$ contains 20 strains all but one of which were received as strains of $S$. dysenteriae and includes the type strain of the species (E37, NCTC 4837). The cluster corresponds to the species $S$. dysenteriae. Three distinct subgroups within this subphenon are evident, and these are related to the serotypes of the strains (Fig. 1).

Subgroup A5(a) $(93.5 \% \mathrm{~S})$ contains five strains of $S$. dysenteriae serotype $2(92.5 \% \mathrm{~S})$ and two mannitol negative strains of $S$. boydii serotype 15. Ewing et al. (1958) noted that mannitol positive $S$. boydii serotype 15 strains could be regarded as a subserotype and biotype within $S$. dysenteriae serotype 2, but preferred to consider these strains as a new serotype of $S$. boydii. The clustering of the mannitol negative variants of $S$. boydii serotype 15 in our study suggests that at least this variety of $S$. boydii serotype 15 should be considered for re-classification as $S$. dysenteriae serotype 2 .

Subgroup A5(b) $(92 \% \mathrm{~S})$ contains two strains of $S$. dysenteriae serotype 4, three ('split') strains of $S$. dysenteriae serotype 6 and one strain of $S$. flexneri serotype 6 . The $S$. dysenteriae serotype 6 strains grouping here $(\mathrm{E} 51 \mathrm{~A} / \mathrm{B} / \mathrm{BX})$ do not show a close relationship to the other $S$. dysenteriae serotype 6 strain (E52). This is the only $S$. dysenteriae serotype included in this study for which strains of the same serotype did not cluster together. However, strain E51 showed certain unusual growth characteristics not found amongst the other shigellae. In particular this strain could not grow on NA without the addition of $0.5 \% \mathrm{NaCl}$. This may explain why the two strains of $S$. dysenteriae serotype 6 did not cluster in the same subphenon.

The $S$. flexneri serotype 6 strain clustering with $S$. dysenteriae is of the aerogenic Newcastle variety (fermentation of glucose and delayed fermentation of dulcitol, with the production of acid and gas; mannitol not fermented). This was the only $S$. flexneri strain of those studied which did not decarboxylate arginine. When originally isolated, strains of this type ('S. newcastle') were classified with the mannitol negative shigellae (later $S$. dysenteriae), but were subsequently transferred to $S$. flexneri because of their antigenic relationship to mannitol positive $S$. flexneri serotype 6 strains. The biochemical similarity of such strains to $S$. dysenteriae is evident here.

Subgroup A5(c) $(92 \%$ S) contains four strains of $S$. dysenteriae serotype 1 and three $S$. dysenteriae strains of unknown serotype. This cluster includes the type strain (NCTC 4837). The characters distinguishing the three subgroups of subphenon A5 are shown in Table 2. 
Table 2. Characters of discriminatory value in differentiating the subgroups of subphenon A5 (S. dysenteriae)

$\begin{array}{lccc}\quad \begin{array}{r}\text { Subgroup } \\ \text { No. of strains }\end{array} & \begin{array}{c}\text { S. dysenteriae } 2 \\ \text { A5(a) }\end{array} & \begin{array}{c}\text { S. dysenteriae } 4 \\ \text { A5(b) }\end{array} & \begin{array}{c}\text { S. dysenteriae } 1 \\ \text { A5(c) }\end{array} \\ \text { Catalase } & 7 & 6 & 7 \\ \text { Indole at } 37{ }^{\circ} \mathrm{C} & + & -(67 \%) & - \\ \text { Indole at } 44^{\circ} \mathrm{C} & + & -(83 \%) & - \\ \text { Acid from glycerol late* } & + & - & - \\ \text { Acid from ribose early* } & + & +(50 \%) & - \\ \text { Acid from ribose late } & +(57 \%) & + & -\end{array}$

,$+ 100 \%$ of strains gave positive reaction;,$- 100 \%$ of strains gave negative reaction. Figures in parenthesis indicate the percentage of strains giving the indicated reaction for variable characters.

* Late, after $6 \mathrm{~d}$; early, 1-6 d.

Subphenon A6 $(89 \% \mathrm{~S})$ contains six $S$. dysenteriae strains and one $S$. flexneri strain. The $S$. dysenteriae strains comprise two strains of serotype 7, three strains of serotype 8 and one strain of the provisional serotype 2000-53. Again, $S$. dysenteriae strains having the same serotype are more closely related than those having different serotypes. The exclusion of $S$. dysenteriae serotype 2000-53 strains fron the genus Shigella has been suggested by Edwards \& Ewing (1972) because strains of this serotype utilize sodium acetate, may be aerogenic, and decarboxylate ornithine. The clustering of strain E60 in our study does not support this proposal. The $S$. flexneri strain clustering in subphenon A6 (strain E81) is a mannitol negative variant of serotype 4a. Such strains have been described by a number of species epithets, viz. 'S. rio' (Weil et al., 1948); 'S. saigonensis' (Rubinsten et al., 1950) and 'S. rabaulensis' (Mumford \& Mohr, 1944), and were at one time classified with the mannitol negative shigellae. Although strain E81 is described as a mannitol negative variant of $S$. flexneri serotype 4a, it does not differ merely in not fermenting mannitol. Strain E81 does not ferment trehalose, but does ferment D-xylose and is ONPG positive. In all these characteristics the strain differs from the $S$. flexneri strains of subphenon A3. Their differences lie not only in the loss of some characters by strain E81 but also in its possession of characters not found in the $S$. flexneri subphenon. This suggests that a more fundamental difference exists between mannitol negative and mannitol positive varieties of $S$. flexneri serotype $4 \mathrm{a}$.

Subphenon A7 $(88.5 \% \mathrm{~S})$ contains only three strains, two $S$. flexneri serotype 6 strains and one strain of $S$. boydii. The $S$. flexneri serotype 6 strains are strain E89 which is of the Manchester variety (which produce acid and gas during fermentation of glucose or mannitol and may ferment dulcitol), and strain E91 which is of the anaerogenic Newcastle variety (only acid is produced on fermentation of glucose or delayed fermentation of dulcitol). It is interesting that the latter does not cluster with the aerogenic Newcastle strain, E90.

The $S$. boydii strain (E31) is of serotype 11. Both it and strain E91 were unusual in being sensitive to the majority (23/24) of antibiotics against which they were tested. Strain E31 ferments both maltose and dulcitol, characters it shares with the two $S$. flexneri serotype 6 strains and which are found only in strains of certain serotypes amongst the species $S$. boydii (Edwards \& Ewing, 1972).

Subphenon A8 $(84 \% \mathrm{~S})$ contains eight strains. Six of these are strains of 'E. alkalescens', one is an 'E. dispar' strain and one is an E. coli strain. This cluster could be equated with the Alkalescens-Dispar group or, alternatively, as all the strains named ' $E$. alkalescens' cluster here the cluster may correspond to a species for which the name $E$. alkalescens could be reproposed.

The E. coli strain (E131) belongs to $O$ antigen group 112 and is of the type originally designated 'S. guanabara' by de Assis (1948). Ewing \& Kauffman (1950) showed a serological relationship (though not complete identity) between ' $S$. guanabara' strains and those of the $E$. coli $\mathrm{O}$ group 112 and re-designated 'S. guanabara' strains as anaerogenic variants of $E$. coli $\mathrm{O} 112$. The biochemical resemblance of these strains to those of the Alkalescens-Dispar group was noted by Ewing \& Kauffman (1950); the clustering of strain E131 in Fig. 1 supports this finding. 
One strain is ungrouped in phenon A; this strain is S. boydii serotype 13 (strain E33). Serotype 13 strains are unusual in possessing an ornithine decarboxylase system (generally only found in $S$. sonne $i$ amongst the shigellae) and aerogenic forms are known. The DNA-DNA hybridization studies of Brenner et al. (1973) showed that $S$. boydii strains of serotype 13 formed a homogeneous group and were unlike the other shigellae. The ungrouped position of strain E33 (Fig. 1) supports this finding and suggests that strains of this serotype may constitute a separate species.

The characteristics of the subphenons of phenon A are given in Table 3 . Phenon B $(82 \% \mathrm{~S})$ contains two strains, one Plesiomonas shigelloides and one Edwardsiella tarda. The taxonomic validity of this cluster cannot be assessed on this information. Phenon $\mathrm{C}(81.5 \% \mathrm{~S})$ contains two of the three Yersinia strains studied. The cluster may be equatable with the genus Yersinia but again the taxonomic validity of the group cannot be assessed. Phenon D $(84 \% \mathrm{~S})$ contains all the Providencia strains and corresponds to the genus Providencia. Three subphenons are evident within this group.

Subphenon D1 $(89 \% \mathrm{~S})$ contains two Providencia alcalifaciens strains (including the type strain, P77 (NCTC 10286)) and five Providencia species. This may be equated with the species $P$. alcalifaciens.

Subphenon D2 $(91 \%$ S) contains five Providencia strains. Three of these strains (P24, P32 and P75) were included in the study of McKell \& Jones (1976) and in that study formed part of the $P$. alcalifaciens cluster. Brenner et al. (1978) in DNA-DNA hybridization studies found two hybridization groups among strains named $P$. alcalifaciens. One group termed by them 'BG1, 2' was characteristically adonitol positive and was typified by the type strain of $\boldsymbol{P}$. alcalifaciens

Table 3. Characteristics of the subphenons of phenons $A, D$ and phenon E, expressed as percentage of positive reactions

$\quad$ Subphenon
No. of strains
Colony diameter <1 mm on BAB
Shiny colonies on BAB
Colony diameter $<1 \mathrm{~mm}$ on NA
Colonies striated on NA
Deposit formed at $37^{\circ} \mathrm{C}$
Ring/pellicle at $37^{\circ} \mathrm{C}$
Growth at $4^{\circ} \mathrm{C}$
Growth at $10^{\circ} \mathrm{C}$
Growth at $45^{\circ} \mathrm{C}$
Motility at $25^{\circ} \mathrm{C}$
Motility at $37^{\circ} \mathrm{C}$
Better growth on BAB than NA
Growth on DOC agar
Black colonies on DOC agar
Growth on selenite agar
Growth on $\mathrm{KCN}$ agar
Growth on $0 \%$ added $\mathrm{NaCl}$
Growth on $5 \%$ added $\mathrm{NaCl}$
Growth in $10^{\circ} \%$ added $\mathrm{NaCl}$
Growth initiation at pH 4
Arginine decarboxylase
Lysine decarboxylase
Ornithine decarboxylase
Arginine dihydrolase
Urease
Catalase
Phenylalanine deaminase
ONPG
Phosphatase
DNAase
Tributyrin hydrolysis
Casein hydrolysis

$\begin{array}{rrrrrrrrrrrr}\mathrm{A} 1 & \mathrm{~A} 2 & \mathrm{~A} 3 & \mathrm{~A} 4 & \mathrm{~A} 5 & \mathrm{~A} 6 & \mathrm{~A} 7 & \mathrm{~A} 8 & \mathrm{D} 1 & \mathrm{D} 2 & \mathrm{D} 3 & \mathrm{E} \\ 17 & 4 & 34 & 27 & 20 & 7 & 3 & 8 & 7 & 5 & 5 & 2 \\ 0 & 0 & 0 & 4 & 0 & 29 & 0 & 0 & 29 & 40 & 20 & 0 \\ 100 & 100 & 100 & 100 & 85 & 100 & 100 & 100 & 100 & 100 & 100 & 100 \\ 0 & 0 & 3 & 7 & 5 & 14 & 0 & 0 & 29 & 80 & 0 & 50 \\ 0 & 0 & 0 & 0 & 0 & 0 & 0 & 0 & 14 & 0 & 0 & 0 \\ 100 & 100 & 100 & 100 & 100 & 100 & 100 & 100 & 100 & 100 & 80 & 100 \\ 0 & 0 & 0 & 0 & 0 & 0 & 0 & 13 & 14 & 0 & 0 & 0 \\ 6 & 25 & 3 & 4 & 5 & 43 & 0 & 13 & 57 & 100 & 40 & 0 \\ 100 & 100 & 76 & 93 & 65 & 100 & 33 & 100 & 100 & 100 & 100 & 100 \\ 94 & 100 & 74 & 89 & 70 & 100 & 67 & 100 & 14 & 20 & 100 & 50 \\ 0 & 0 & 0 & 0 & 0 & 0 & 0 & 0 & 100 & 20 & 80 & 100 \\ 0 & 0 & 0 & 0 & 0 & 0 & 0 & 0 & 57 & 0 & 80 & 100 \\ 18 & 25 & 38 & 12 & 50 & 14 & 67 & 0 & 29 & 100 & 20 & 50 \\ 94 & 100 & 94 & 100 & 90 & 100 & 0 & 100 & 100 & 100 & 100 & 100 \\ 0 & 0 & 0 & 0 & 0 & 0 & 0 & 0 & 0 & 0 & 0 & 50 \\ 82 & 100 & 21 & 96 & 50 & 100 & 33 & 88 & 100 & 100 & 100 & 100 \\ 100 & 100 & 100 & 100 & 100 & 100 & 67 & 100 & 86 & 100 & 100 & 100 \\ 100 & 100 & 100 & 100 & 95 & 100 & 100 & 100 & 100 & 100 & 100 & 100 \\ 100 & 100 & 88 & 96 & 75 & 100 & 67 & 100 & 100 & 80 & 100 & 100 \\ 0 & 0 & 0 & 0 & 0 & 0 & 0 & 0 & 0 & 0 & 40 & 0 \\ 12 & 0 & 0 & 0 & 0 & 0 & 0 & 0 & 29 & 0 & 0 & 0 \\ 65 & 75 & 29 & 81 & 40 & 86 & 67 & 88 & 0 & 0 & 0 & 0 \\ 0 & 0 & 0 & 0 & 0 & 0 & 0 & 75 & 0 & 0 & 0 & 0 \\ 88 & 25 & 0 & 7 & 10 & 14 & 0 & 13 & 0 & 20 & 0 & 0 \\ 0 & 0 & 0 & 0 & 0 & 0 & 0 & 0 & 0 & 0 & 40 & 0 \\ 0 & 0 & 0 & 0 & 0 & 0 & 0 & 0 & 0 & 0 & 0 & 100 \\ 100 & 100 & 100 & 78 & 45 & 71 & 100 & 100 & 100 & 100 & 100 & 100 \\ 0 & 0 & 0 & 0 & 0 & 0 & 0 & 0 & 100 & 100 & 40 & 100 \\ 88 & 25 & 3 & 19 & 20 & 14 & 0 & 75 & 0 & 0 & 20 & 50 \\ 18 & 0 & 0 & 22 & 15 & 57 & 33 & 100 & 100 & 40 & 100 & 100 \\ 0 & 0 & 0 & 0 & 0 & 0 & 0 & 0 & 100 & 80 & 100 & 100 \\ 94 & 100 & 68 & 67 & 25 & 86 & 0 & 63 & 86 & 40 & 60 & 100 \\ 0 & 25 & 0 & 4 & 0 & 0 & 0 & 25 & 0 & 0 & 0 & 0\end{array}$


Table 3.-(continued)

Indole at $37^{\circ} \mathrm{C}$

Indole at $44^{\circ} \mathrm{C}$

MR

VP

$\mathrm{H}_{2} \mathrm{~S}$ from thiosulphate

$\mathrm{H}_{2} \mathrm{~S}$ from cysteine

Gas from adonitol

Gas from dulcitol

Gas from glucose

Gas from glycerol

Gas from mannitol

Nitrate reduced

Nitrite reduced

Sensitivity to sulphafurazole

Sensitivity to ampicillin

Sensitivity to cloxacillin

Sensitivity to erythromycin

Sensitivity to methicillin

Sensitivity to novobiocin

Sensitivity to oleandomycin

Sensitivity to penicillin $G$

Sensitivity to furazolidone

Sensitivity to carbenicillin

Sensitivity to colistin sulphate

Sensitivity to nitrofurantoin

Sensitivity to polymyxin B

Sensitivity to tetracycline

Sensitivity to cephaloridine

Sensitivity to chloramphenicol

Sensitivity to chlortetracycline

Sensitivity to oxytetracycline

Sensitivity to streptomycin

Sensitivity to sulphamethoxazole/

trimethoprim

Utilization of acetate

Utilization of 2-oxoglutarate

Utilization of 3-hydroxybenzoate

Utilization of 4-hydroxybenzoate

Utilization of carnitine

Utilization of cellobiose

Utilization of citrate

Utilization of cysteine

Utilization of ethanol

Utilization of fructose

Utilization of galactose

Utilization of galacturonate

Utilization of gluconate

Utilization of glutamate

Utilization of lactose

Utilization of malate

Utilization of mucate

Utilization of phenylalanine

Utilization of propionate

Utilization of raffinose

Utilization of starch

Utilization of succinate

Utilization of L-tartrate

Utilization of meso-tartrate

Utilization of aesculin

Utilization of alginate

Acid from adonitol early

Acid from adonitol late

Acid from aesculin early

$\begin{array}{rrrrrrrrrrrr}\mathrm{A} 1 & \mathrm{~A} 2 & \mathrm{~A} 3 & \mathrm{~A} 4 & \mathrm{~A} 5 & \mathrm{~A} 6 & \mathrm{~A} 7 & \mathrm{~A} 8 & \mathrm{D} 1 & \mathrm{D} 2 & \mathrm{D} 3 & \mathrm{E} \\ 0 & 75 & 97 & 11 & 40 & 100 & 33 & 100 & 100 & 100 & 100 & 100 \\ 0 & 75 & 82 & 11 & 35 & 100 & 33 & 100 & 29 & 0 & 100 & 0 \\ 100 & 100 & 94 & 100 & 100 & 100 & 100 & 100 & 100 & 100 & 100 & 100 \\ 0 & 0 & 6 & 0 & 5 & 0 & 0 & 0 & 0 & 0 & 0 & 0 \\ 0 & 0 & 0 & 0 & 0 & 0 & 0 & 0 & 14 & 0 & 0 & 0 \\ 6 & 75 & 0 & 0 & 0 & 29 & 0 & 38 & 0 & 0 & 0 & 0 \\ 0 & 0 & 0 & 0 & 0 & 0 & 0 & 0 & 43 & 0 & 0 & 50 \\ 0 & 0 & 0 & 0 & 0 & 0 & 33 & 0 & 0 & 0 & 0 & 0 \\ 0 & 0 & 0 & 4 & 0 & 0 & 33 & 0 & 57 & 40 & 0 & 50 \\ 0 & 0 & 0 & 0 & 0 & 0 & 33 & 0 & 0 & 0 & 0 & 0 \\ 0 & 0 & 0 & 0 & 0 & 0 & 33 & 0 & 0 & 0 & 0 & 50 \\ 100 & 100 & 100 & 100 & 100 & 100 & 100 & 100 & 100 & 80 & 100 & 100 \\ 100 & 100 & 88 & 93 & 100 & 100 & 100 & 100 & 100 & 80 & 100 & 100 \\ 0 & 0 & 35 & 56 & 65 & 43 & 67 & 13 & 0 & 0 & 0 & 0 \\ 59 & 100 & 100 & 100 & 100 & 100 & 100 & 100 & 71 & 100 & 60 & 50 \\ 0 & 0 & 0 & 0 & 0 & 0 & 67 & 0 & 14 & 20 & 0 & 0 \\ 0 & 0 & 15 & 41 & 35 & 43 & 100 & 0 & 0 & 0 & 0 & 0 \\ 0 & 0 & 0 & 0 & 0 & 0 & 67 & 0 & 29 & 40 & 20 & 50 \\ 0 & 100 & 24 & 70 & 20 & 86 & 67 & 13 & 14 & 80 & 20 & 50 \\ 0 & 0 & 0 & 0 & 0 & 0 & 67 & 0 & 0 & 0 & 0 & 0 \\ 0 & 0 & 12 & 26 & 35 & 14 & 33 & 13 & 14 & 20 & 0 & 0 \\ 100 & 100 & 100 & 100 & 100 & 100 & 100 & 100 & 100 & 40 & 40 & 50 \\ 88 & 100 & 100 & 96 & 100 & 100 & 100 & 100 & 71 & 100 & 100 & 100 \\ 100 & 100 & 100 & 100 & 100 & 100 & 100 & 100 & 14 & 80 & 0 & 0 \\ 100 & 100 & 100 & 100 & 100 & 100 & 100 & 100 & 100 & 80 & 20 & 50 \\ 100 & 100 & 100 & 100 & 100 & 100 & 100 & 100 & 14 & 80 & 0 & 0 \\ 88 & 100 & 88 & 96 & 100 & 100 & 100 & 100 & 43 & 100 & 0 & 50 \\ 88 & 100 & 100 & 100 & 100 & 100 & 100 & 100 & 14 & 60 & 0 & 0 \\ 100 & 100 & 100 & 100 & 100 & 100 & 100 & 100 & 100 & 100 & 80 & 50 \\ 88 & 100 & 88 & 100 & 100 & 100 & 100 & 100 & 43 & 100 & 0 & 50 \\ 88 & 100 & 88 & 96 & 100 & 100 & 100 & 100 & 43 & 100 & 0 & 50 \\ 100 & 100 & 97 & 93 & 95 & 100 & 100 & 88 & 100 & 100 & 60 & 50\end{array}$

$\begin{array}{rrrrrrrrrrrr}59 & 75 & 76 & 100 & 100 & 100 & 100 & 100 & 100 & 100 & 60 & 0\end{array}$

$\begin{array}{llllllllllll}65 & 100 & 62 & 85 & 65 & 86 & 100 & 100 & 100 & 80 & 100 & 100\end{array}$

$\begin{array}{llllllllllll}94 & 75 & 68 & 67 & 40 & 57 & 100 & 63 & 14 & 40 & 100 & 50\end{array}$

$\begin{array}{rrrrrrrrrrrr}0 & 0 & 0 & 0 & 0 & 0 & 0 & 63 & 0 & 0 & 0 & 0\end{array}$

$\begin{array}{rrrrrrrrrrrr}0 & 0 & 0 & 0 & 0 & 0 & 0 & 63 & 0 & 0 & 0 & 0\end{array}$

$\begin{array}{rrrrrrrrrrrr}0 & 0 & 0 & 0 & 0 & 0 & 0 & 13 & 57 & 0 & 100 & 50\end{array}$

$\begin{array}{rrrrrrrrrrrr}0 & 50 & 0 & 0 & 0 & 0 & 0 & 13 & 0 & 0 & 0 & 0\end{array}$

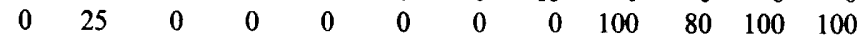

$\begin{array}{rrrrrrrrrrrr}0 & 0 & 0 & 0 & 0 & 0 & 0 & 25 & 0 & 0 & 0 & 50 \\ 0 & 25 & 0 & 0 & 0 & 0 & 0 & 0 & 0 & 0 & 0 & 0\end{array}$

$\begin{array}{rrrrrrrrrrrr}100 & 100 & 97 & 96 & 95 & 100 & 100 & 100 & 86 & 100 & 100 & 100\end{array}$

$\begin{array}{llllllllllll}100 & 100 & 97 & 96 & 100 & 100 & 100 & 88 & 29 & 100 & 100 & 100\end{array}$

$\begin{array}{llllllllllll}65 & 100 & 91 & 52 & 25 & 71 & 100 & 100 & 14 & 0 & 0 & 50\end{array}$

$\begin{array}{rllllllllll}100 & 100 & 91 & 96 & 90 & 100 & 100 \cdot 100 & 100 & 100 & 100 & 100\end{array}$

$\begin{array}{llllllllllll}100 & 100 & 26 & 67 & 30 & 71 & 100 & 88 & 100 & 100 & 100 & 100\end{array}$

$\begin{array}{llllllllllll}6 & 75 & 3 & 0 & 10 & 0 & 0 & 25 & 0 & 0 & 20 & 50\end{array}$

$\begin{array}{rrrrrrrrrrrr}100 & 100 & 91 & 89 & 95 & 100 & 100 & 100 & 86 & 100 & 100 & 100\end{array}$

$\begin{array}{rrrrrrrrrrrr}6 & 100 & 6 & 4 & 5 & 43 & 0 & 88 & 0 & 0 & 0 & 0 \\ 0 & 0 & 0 & 0 & 0 & 0 & 0 & 0 & 43 & 40 & 100 & 50\end{array}$

$\begin{array}{rrrrrrrrrrrr}0 & 25 & 0 & 0 & 0 & 0 & 0 & 38 & 14 & 0 & 60 & 50 \\ 0 & 75 & 76 & 4 & 10 & 0 & 0 & 38 & 0 & 0 & 20 & 0\end{array}$

$\begin{array}{rrrrrrrrrrrr}0 & 75 & 76 & 4 & 10 & 0 & 0 & 38 & 0 & 0 & 20 & 0 \\ 6 & 0 & 21 & 0 & 0 & 43 & 0 & 25 & 0 & 0 & 0 & 0\end{array}$

$\begin{array}{rrrrrrrrrrrr}100 & 100 & 91 & 96 & 90 & 100 & 100 & 100 & 100 & 100 & 100 & 100\end{array}$

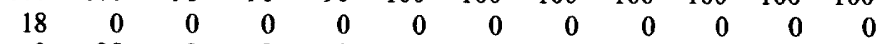

$\begin{array}{llllllllllll}0 & 25 & 0 & 0 & 0 & 14 & 0 & 13 & 0 & 0 & 0 & 50\end{array}$

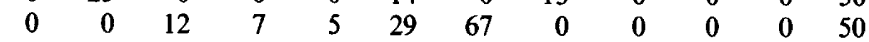

$\begin{array}{rrrrrrrrrrrr}0 & 0 & 0 & 0 & 0 & 0 & 0 & 13 & 0 & 0 & 0 & 0 \\ 0 & 0 & 0 & 0 & 0 & 0 & 0 & 0 & 100 & 0 & 0 & 100\end{array}$

$\begin{array}{rrrrrrrrrrrr}0 & 0 & 0 & 0 & 0 & 0 & 0 & 0 & 100 & 0 & 0 & 100 \\ 0 & 0 & 0 & 0 & 0 & 0 & 0 & 0 & 84 & 0 & 20 & 0\end{array}$

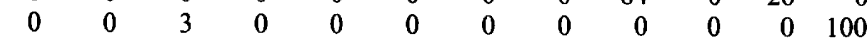


Table 3.-(continued)

Subphenon

Acid from aesculin late Acid from D-arabinose early Acid from D-arabinose late Acid from L-arabinose early Acid from L-arabinose late Acid from arabitol early Acid from arabitol late Acid from arbutin early Acid from arbutin late Acid from cellobiose early Acid from cellobiose late Acid from dextrin early Acid from dextrin late Acid from dulcitol early Acid from dulcitol late Acid from erythritol early Acid from fructose late Acid from galactose early Acid from galactose late Acid from glycerol early Acid from glycerol late Acid from inositol early Acid from inositol late Acid frominulin early Acid frominulin late Acid from lactose early Acid from lactose late Acid from maltose early Acid from maltose late Acid from mannitol early Acid from mannitol late Acid from mannose late Acid from melibiose early Acid from melibiose late Acid from mucate early Acid from raffinose early Acid from raffinose late Acid from rhamnose early Acid from rhamnose late Acid from ribose early Acid from ribose late Acid from salicin early Acid from salicin late Acid from sorbitol early Acid from sorbitol late Acid from L-sorbose early Acid from L-sorbose late Acid from starch early Acid from starch late Acid from sucrose early Acid from sucrose late Acid from trehalose early Acid from trehalose late Acid from D-xylose early Acid from D-xylose late

\begin{tabular}{|c|c|c|c|c|c|c|c|c|c|c|c|}
\hline $\mathrm{Al}$ & A2 & $\mathrm{A} 3$ & A4 & A5 & A6 & A7 & A8 & D1 & D2 & D3 & \\
\hline 0 & 0 & 3 & 0 & 0 & 0 & 0 & 25 & 84 & 100 & 60 & 10 \\
\hline 35 & 100 & 0 & 4 & 0 & 14 & 0 & 88 & 0 & 0 & 0 & 50 \\
\hline 88 & 75 & O & 7 & 5 & 14 & 0 & 75 & 0 & 0 & 0 & \\
\hline 100 & 100 & 68 & 96 & 10 & 100 & 100 & 100 & 0 & 0 & 0 & \\
\hline 0 & 100 & 56 & 96 & 20 & 100 & 100 & 88 & 0 & 0 & 0 & \\
\hline & 0 & 0 & 0 & 0 & 0 & 0 & 0 & 0 & 0 & 0 & 100 \\
\hline 0 & 0 & 0 & 0 & 0 & 0 & 0 & 0 & 0 & & 0 & 50 \\
\hline 35 & 0 & 3 & 0 & 0 & 0 & 0 & 50 & 0 & 0 & 0 & 100 \\
\hline 94 & 75 & 6 & 11 & 5 & 0 & 0 & 88 & . & 0 & 20 & 100 \\
\hline 6 & 0 & 0 & 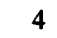 & 0 & 0 & 0 & 0 & 0 & . & 100 & \\
\hline 12 & 0 & 0 & 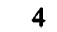 & 0 & 0 & 0 & 13 & 0 & 0 & 100 & 50 \\
\hline 0 & 0 & 3 & 0 & 0 & 0 & 0 & & 0 & 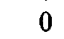 & 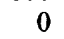 & \\
\hline 0 & 25 & 3 & 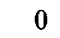 & 0 & 14 & 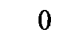 & 13 & 0 & & 0 & \\
\hline 0 & 0 & 0 & 30 & 5 & 0 & 67 & 8 & 0 & & & \\
\hline 0 & 0 & 0 & 33 & 5 & 0 & 100 & 38 & 0 & & 0 & \\
\hline 0 & 0 & 0 & 0 & $v$ & 0 & & & 0 & & 0 & 00 \\
\hline 100 & 100 & 100 & 100 & 100 & 100 & 100 & 100 & 71 & 100 & 100 & 100 \\
\hline 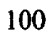 & 100 & 100 & 100 & 100 & 100 & 100 & 10 & 0 & & 00 & 100 \\
\hline & 100 & 100 & 100 & 100 & n & 100 & 1 & 43 & 00 & 00 & \\
\hline 100 & 100 & 38 & 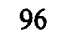 & 80 & 100 & 100 & 100 & 100 & 100 & 00 & 100 \\
\hline 0 & 100 & 73 & 9 & 85 & 86 & 100 & 100 & & 100 & 40 & 50 \\
\hline 0 & 0 & . & 0 & 0 & 0 & 0 & 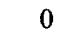 & 0 & 0 & 00 & 100 \\
\hline 0 & 0 & 0 & 0 & 0 & 0 & 0 & 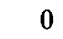 & & & & \\
\hline 0 & 0 & 0 & c & 0 & 0 & 0 & c & & & & \\
\hline 0 & 0 & 0 & 0 & 0 & 0 & 0 & 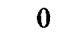 & & & & \\
\hline 0 & 0 & 0 & 0 & 0 & 0 & 0 & 1. & & & & 50 \\
\hline 82 & 25 & 0 & 7 & 5 & 0 & 0 & 2 & & & & \\
\hline 100 & 100 & 50 & 11 & 0 & 71 & 67 & 10 & 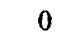 & & & \\
\hline 0 & if & 4 & & 35 & & 100 & & 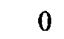 & & ( & \\
\hline 94 & 100 & 10 & 5 & & & 6 & & & & 0 & 100 \\
\hline 94 & 100 & 10 & 6 & ( & 0 & 6 & & & & & \\
\hline 100 & 100 & & 100 & 100 & 86 & 100 & 10 & 100 & 100 & 100 & 10 \\
\hline 12 & 7 & & & 10 & & & & & & & \\
\hline 100 & 7 & 74 & t & & 1 & & & & & 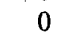 & \\
\hline 0 & 25 & & & & & & & & & & \\
\hline 6 & 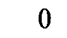 & 3 & & & & & & & & 20 & \\
\hline 76 & 0 & 47 & & & & & & & & & \\
\hline 100 & 100 & & & & 5 & & & & & & \\
\hline 71 & 2 & 3 & & & 43 & & & & & & 50 \\
\hline 00 & 10 & 62 & 9 & & $\mathrm{Mo}$ & D. & 100 & 0 & 00 & 100 & 100 \\
\hline 00 & 100 & 1 & 7 & 60 & 100 & 100 & 1 & 00 & 00 & 100 & 100 \\
\hline 0 & 0 & 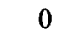 & & & & & & & & & 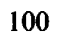 \\
\hline 0 & 0 & 3 & & & & & & & & 40 & 100 \\
\hline 0 & 100 & 2 & & 5 & & & & & 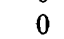 & 100 & \\
\hline 6 & 0 & 15 & & 65 & & 100 & & & & 60 & \\
\hline 0 & 0 & 0 & & 0 & & & & & & & \\
\hline 6 & 25 & 0 & 3 & 0 & 43 & & 25 & & & & \\
\hline 0 & 0 & 3 & 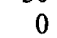 & & & & & & & & \\
\hline 53 & 2 & 3 & 0 & & & & & & & & \\
\hline 17 & 2 & 3 & & & & & 2 & 5 & & 100 & 80 \\
\hline 82 & 2 & 3 & & & & & & 100 & 80 & & $J$ \\
\hline 02 & 10 & 9 & 9 & 7 & 5 & 3 & 10 & & 0 & 100 & \\
\hline 00 & 10 & 91 & 8 & 85 & 4 & 100 & & 14 & & 20 & \\
\hline 6 & 100 & 0 & 1 & 0 & 4 & 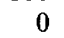 & 8 & $\ldots$ & & 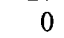 & \\
\hline & . & 0 & 50 & 0 & 57 & 33 & 38 & 0 & 0 & 0 & \\
\hline
\end{tabular}

All of the strains grew at $37^{\circ} \mathrm{C}$; in the presence of $0.5 \%$ added $\mathrm{NaCl}$; initiated growth at $\mathrm{pH} 6, \mathrm{pH} 8, \mathrm{pH} 10$; were sensitive to nalidixic acid, gentamicin, kanamycin and neomycin; produced acid from fructose and mannose early; produced acid from glucose aerobically and anaerobically; produced acid from $N$-acetylglucosamine early and late; produced ammonia from peptone; utilized pyruvate.

None of the strains produced red pigment on BAB or on NA; exhibited striations on colonies on BAB; exhibited swarming at $25^{\circ} \mathrm{C}$ or $30^{\circ} \mathrm{C}$; produced gas from inositol, starch or maltose; liquefied gelatin; gave a positive oxidase reaction; gave a positive result in the Eijkman test; utilized adipate, benzoate, hippurate, oxalate or Dtartrate; produced acid from amygdalin, glycogen, melezitose, $\alpha$-methyl-D-glucoside or L-xylose. 
Table 4. Characters differentiating subphenons of phenon $D$ (Providencia) and phenon E (Prot. rettgeri)

\begin{tabular}{|c|c|c|c|c|}
\hline $\begin{array}{r}\text { Phenon/subphenon } \\
\text { No. of strains }\end{array}$ & $\begin{array}{c}\mathrm{D} 1 \\
7\end{array}$ & $\begin{array}{c}\mathrm{D} 2 \\
5\end{array}$ & $\begin{array}{c}\mathrm{D} 3 \\
5\end{array}$ & $\begin{array}{l}E \\
2\end{array}$ \\
\hline Growth at $4^{\circ} \mathrm{C}$ & $+(57 \%)$ & + & $+(40 \%)$ & - \\
\hline Motility at $37^{\circ} \mathrm{C}$ & $+(57 \%)$ & - & $+(80 \%)$ & + \\
\hline Urease & - & - & - & + \\
\hline Indole at $44^{\circ} \mathrm{C}$ & $+(29 \%)$ & - & + & - \\
\hline Sensitivity to tetracycline & $+(43 \%)$ & + & - & $+(50 \%)$ \\
\hline Sensitivity to chlortetracycline & $+(43 \%)$ & + & - & $+(50 \%)$ \\
\hline Sensitivity to oxytetracycline & $+(43 \%)$ & + & - & $+(50 \%)$ \\
\hline Sensitivity to sulphamethoxazole/trimethoprim & + & + & $+(60 \%)$ & - \\
\hline Utilization of carnitine & $+(57 \%)$ & - & + & $+(50 \%)$ \\
\hline Acid from adonitol early & + & - & - & + \\
\hline Acid from aesculin early & - & - & - & + \\
\hline Acid from arabitol early & - & - & - & + \\
\hline Acid from arbutin early & - & - & - & + \\
\hline Acid from arbutin late & - & - & $+(20 \%)$ & + \\
\hline Acid from cellobiose early & - & - & + & - \\
\hline Acid from cellobiose late & - & - & + & $+(50 \%)$ \\
\hline Acid from erythritol early & - & - & - & + \\
\hline Acid from galactose early & - & + & + & + \\
\hline Acid from inositol early & - & - & + & + \\
\hline Acid from mannitol & - & - & - & + \\
\hline Acid from salicin early & - & - & - & + \\
\hline Acid from salicin late & - & - & $+(40 \%)$ & + \\
\hline Acid from sorbitol early & - & - & + & - \\
\hline Acid from trehalose early & - & - & + & - \\
\hline
\end{tabular}

,$+ 100 \%$ strains gave positive reactions;,$- 0 \%$ strains gave positive reactions. Figures in parentheses indicate the percentage of positive reactions for variable characters.

(P77, NCTC 10286, ATCC 9886). Brenner et al. (1978) suggested $P$. alcalifaciens strain ATCC 12013, as the designated type strain for their other hybridization group 'BG3'. This strain is strain NCTC 8113 (i.e. strain P24) which in our study groups in subphenon D2. The two subphenons D1 and D2 therefore appear to be equatable with the two hybridization groups found among $P$. alcalifaciens strains by Brenner et al. (1978).

Subphenon D3 $(88 \% \mathrm{~S})$ contains four strains of $P$. stuartii (including NCTC 10318, designated as $P$. stuartii by Ewing 1963), and one received as a Providencia species. It thus corresponds to the species $P$. stuartii. The characteristics of these three subphenons and the characters distinguishing them are shown in Tables 3 and 4, respectively. It should be noted that strains of subphenon D1 are adonitol positive, as was the 'BG1, 2' hybridization group of Brenner et al. (1978), and this character distinguishes it from subphenon $\mathrm{D} 2$.

Phenon E $(81.5 \% \mathrm{~S})$ contains two strains of Prot. rettgeri. These show a very close association with the Providencia cluster (Phenon D) from which it is separated at the $80 \% \mathrm{~S}$ level (Figs 1 and 2; Tables 3 and 4). It is questionable whether the Prot. rettgeri strains should be regarded as constituting a separate taxon or whether they should be considered to be part of the Providencia cluster. The close relationship of Prot. rettgeri strains to the genus Providencia was seen in the numerical study of McKell \& Jones (1976) and in the molecular studies of Brenner et al. (1978). Indeed, both names, Prot. rettgeri and Prov. rettgeri, are included in the Approved Lists of Bacterial Names (Skerman et al., 1980). Phenon F (84.5\%S) contains two Citrobacter strains and corresponds to the genus Citrobacter. Phenon G $(84 \% \mathrm{~S})$ contains two of the three Salmonella strains in the study. The type strain of the type species is present in the cluster and so the phenon corresponds to this genus. Phenon $\mathrm{H}(84 \% \mathrm{~S})$ contains five $E$. coli strains including the type strain, and one strain of ' $E$. dispar'. The cluster can be equated with the genus Escherichia. Phenon $\mathrm{J}(89.5 \% \mathrm{~S})$ contains two strains received as 'Enterobacter liquefaciens'. Phenon $\mathrm{K}$ $(82.5 \% \mathrm{~S})$ contains representatives of three species of the genus Proteus: P. vulgaris (two strains including the type strain); P. morganii (one strain) and P. mirabilis (two strains). The cluster thus 
Table 5. Characters of greatest discriminatory value in distinguishing phenon A from the other groups in the study

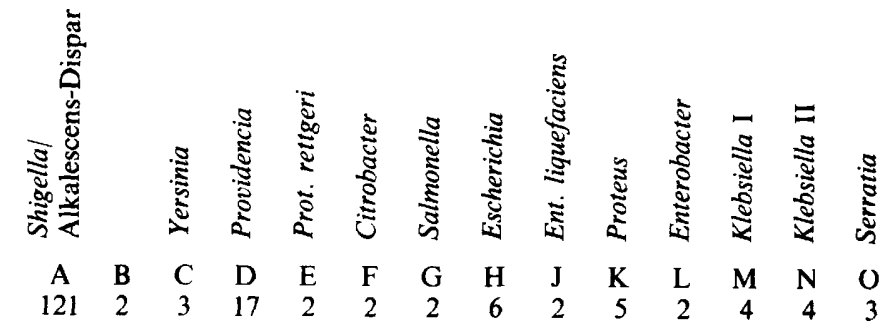

Growth at $4{ }^{\circ} \mathrm{C}$

Swarming at $25^{\circ} \mathrm{C}$

Motility at $25^{\circ} \mathrm{C}$

Motility at $37^{\circ} \mathrm{C}$

Growth in $5 \% \mathrm{NaCl}$

Growth at $\mathrm{pH} 4$

Lysine decarboxylase

Arginine dihydrolase

Urease

Phenylalanine deaminase

DNAase

Gelatin hydrolysis

Casein hydrolysis

VP

$\mathrm{H}_{2} \mathrm{~S}$ from cysteine

Gas from adonitol

Gas from glucose

Gas from glycerol

Gas from maltose

Gas from mannitol

Sensitivity to Ampicillin

Sensitivity to Carbenicillin

Sensitivity to Colistin sulphate

Sensitivity to Polymyxin B

Sensitivity to Tetracycline

Sensitivity to Cephaloridine

Sensitivity to Chlortetracycline

Sensitivity to Oxytetracycline

Sensitivity to Streptomycin

Utilization of 3-hydroxybenzoate

Utilization of 4-hydroxybenzoate

Utilization of cellobiose

Utilization of citrate

Utilization of ethanol

Utilization of hippurate

Utilization of lactose

Utilization of malate

Utilization of phenylalanine

Utilization of propionate

Utilization of aesculin

Acid from adonitol early

Acid from aesculin early

Acid from aesculin late

Acid from amygdalin early

Acid from amygdalin late

Acid from arabitol early

Acid from arbutin early

Acid from cellobiose early

Acid from cellobiose late

Acid from erythritol early

Acid from fructose late

Acid from galactose late

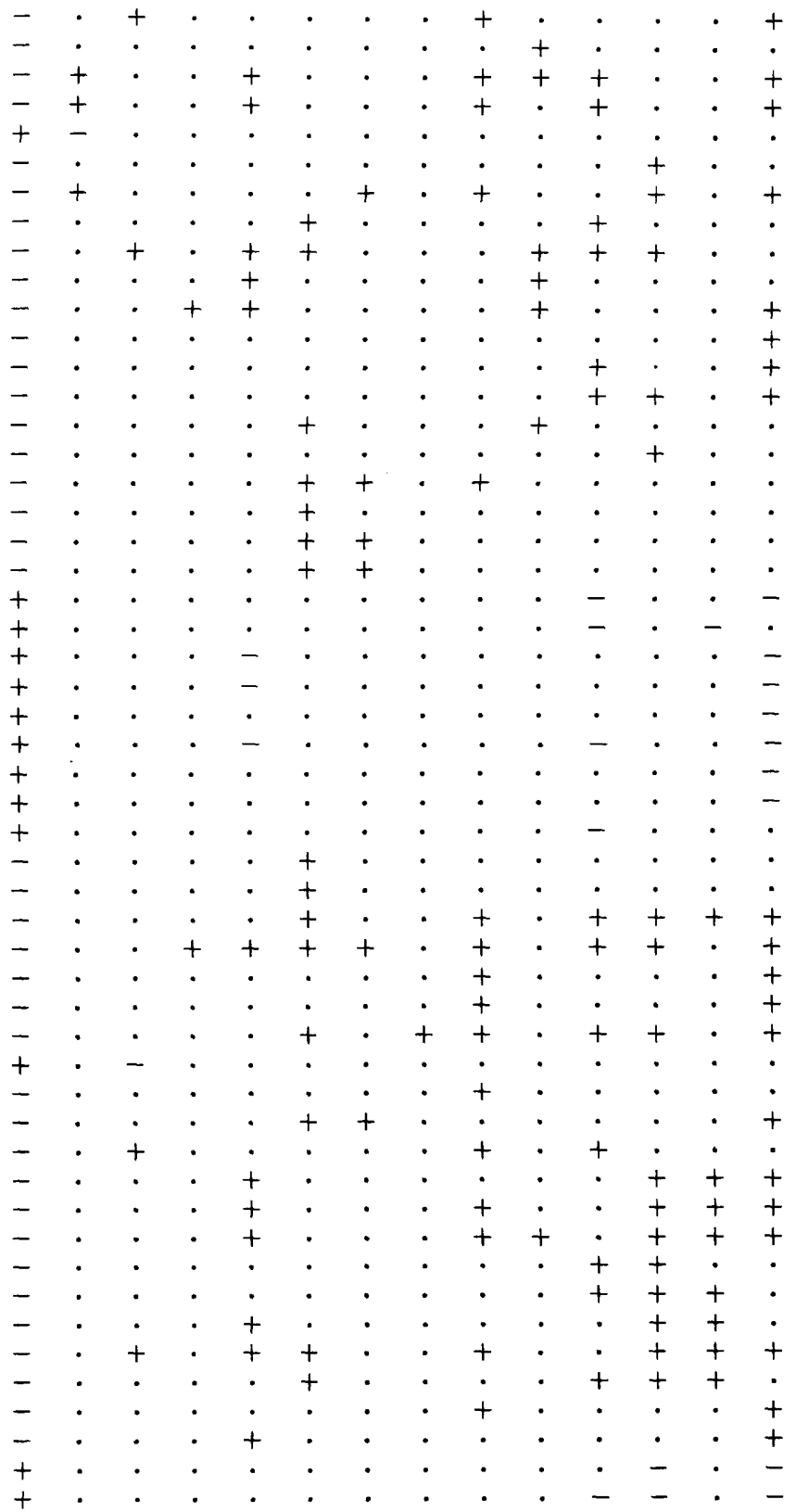


Table 5.-(continued)

\begin{tabular}{|c|c|c|c|c|c|c|c|c|c|c|c|c|c|c|}
\hline Phenon & A & B & $\mathrm{C}$ & $\mathrm{D}$ & E & $\mathrm{F}$ & G & $\mathrm{H}$ & $\mathbf{J}$ & $\mathrm{K}$ & $\mathrm{L}$ & $\mathbf{M}$ & $\mathrm{N}$ & $\mathrm{O}$ \\
\hline Acid from glucose late & + & 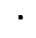 & $\cdot$ & $\cdot$ & $\cdot$ & 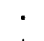 & $\cdot$ & $\cdot$ & • & · & - & - & 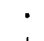 & \\
\hline Acid from inositol early & - & $\cdot$ & - & $\cdot$ & + & + & $\cdot$ & - & + & $\cdot$ & + & + & + & + \\
\hline Acid from inositol late & - & • & • & • & $\cdot$ & $\cdot$ & $\cdot$ & $\dot{r}$ & + & $\cdot$ & · & • & + & \\
\hline Acid from lactose early & - & - & - & $\cdot$ & $\cdot$ & + & $\cdot$ & + & $\cdot$ & $\cdot$ & + & + & + & - \\
\hline $\begin{array}{l}\text { Acid from } \alpha \text {-methyl-D- } \\
\text { glucoside early }\end{array}$ & - & • & · & • & $\cdot$ & + & • & 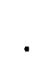 & $0^{\circ}$ & $\cdot$ & $\cdot$ & + & $\cdot$ & \\
\hline Acid from $N$-acetylglucosamine late & + & • & - & - & $\cdot$ & $\cdot$ & - & $\cdot$ & $\cdot$ & - & - & - & - & - \\
\hline Acid from salicin early & - & $\cdot$ & + & - & + & + & - & - & + & $\cdot$ & + & + & + & + \\
\hline Acid from salicin late & - & $\cdot$ & + & - & + & + & • & + & + & $\cdot$ & $\cdot$ & + & + & + \\
\hline Acid from starch early & - & $\cdot$ & $\cdot$ & • & $\cdot$ & $\cdot$ & • & $\cdot$ & $\cdot$ & $\cdot$ & $\cdot$ & $\cdot$ & + & 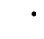 \\
\hline Acid from starch late & - & • & $\cdot$ & - & $\cdot$ & $\cdot$ & • & • & + & • & • & $\cdot$ & t & $\cdot$ \\
\hline Acid from sucrose early & - & - & $\cdot$ & - & . & + & $\cdot$ & $\cdot$ & + & + & + & + & $\cdot$ & $t$ \\
\hline
\end{tabular}

,$+ \geqslant 90 \%$ strains give positive reactions;,$- \leqslant 10 \%$ gives positive reactions.

corresponds to the genus Proteus but the species distinction is not good. The clustering of Prot. morganii with Prot. vulgaris and Prot. mirabilis supports the findings of Johnson et al. (1975). It is not in agreement with the results of the numerical study of McKell \& Jones (1976), which resulted in the clustering of Prot. morganii as a distinct taxon well separated from Prot. vulgaris and Prot. mirabilis. The study of McKell \& Jones (1976) included many more strains of the genus Proteus and so is likely to be a more accurate picture of the interrelationships in the ProteusProvidence region than this present study. The hybridization studies of Brenner et al. (1978) also indicate that Prot. morganii is different from the genus Proteus (Prot. vulgaris and Prot. mirabilis) and from members of the genus Providencia. Brenner et al. (1978) suggested that Prot. morganii strains be reclassified in the genus Morganella as first suggested by Kauffman (1954).

Phenon L $(88.5 \% \mathrm{~S})$ contains two strains including the type strain of Enterobacter cloacae. The other Enterobacter strains studied do not cluster here, but since Ent. cloacae is the type species of the genus Enterobacter, the phenon may be equated with this genus. Phenon M $(80.5 \% \mathrm{~S})$ contains two Klebsiella strains, one strain of Enterobacter and one Salmonella strain. The clustering of the strain of Sal. paratyphi with the Klebsiella strains and not in phenon G with the other Salmonella strains, was unexpected. It is probable that the culture tested (K43) was not as originally described but at some time had been contaminated or confused with a Klebsiella strain. Attempts to compare our culture of this strain with another freeze-dried culture of K43 maintained at Leicester proved impossible as the stored strain failed to grow.

The two Klebsiella strains clustering in phenon $\mathbf{M}$ are ' $K$. aerogenes' and ' $K$. edwardsii'. The close association of these two species was seen in the study of Bascomb et al. (1971) who considered them to be the same species. The association of Ent. aerogenes with these strains was also seen in the study of Bascomb et al. (1971) and led these authors to suggest that Ent. aerogenes be included in the genus Klebsiella as K. mobilis. The strain of Ent. aerogenes (NCTC 10006) is the designated type strain of $K$. mobilis (Skerman et al., 1980). Phenon N $(82 \% \mathrm{~S})$ contains three Klebsiella strains representing the species $K$. pneumoniae (capsular type 3 ) and $K$. ozaenae. Related to this phenon at just below $80 \% \mathrm{~S}$ is a strain of $K$. rhinoscleromatis it is considered to be part of phenon $\mathbf{N}$. The association of $K$. pneumoniae with $K$. ozaenae and $K$. rhinoscleromatis is not in accord with the findings of Bascomb et al. (1971).

The clustering of klebsiellae in our study resembles most closely the groupings suggested by Henriksen (1954). He proposed two groups for the Klebsiella strains based on their biochemical characteristics, one containing $K$. pneumoniae capsular types 1 and 2 (equivalent to the species ' $K$. aerogenes' and ' $K$. edwardsii'), and the other containing $K$. pneumoniae capsular type $3, K$. ozaenae and $K$. rhinoscleromatis. These would be equivalent to phenons $\mathrm{M}$ and $\mathrm{N}$, respectively, in this study. Phenon $\mathrm{O}(89 \% \mathrm{~S})$ contains three strains including the type strain of $S$. marcescens, and this cluster corresponds to the genus Serratia. The characters distinguishing each of the phenons $\mathrm{B}-\mathrm{O}$ from phenon $\mathrm{A}$ are shown in Table 5. 


\section{DISCUSSION}

The purpose of the study was to determine the number and nature of the groupings which could be defined phenotypically within the genus Shigella and to ascertain whether they could be distinguished from each other and from other taxa within the family Enterobacteriaceae, notably the Alkalescens-Dispar group, E. coli and the genus Providencia.

Within the genus Shigella at least four taxospecies (Ravin, 1963) are evident. In our opinion subphenons A5 and A6 correspond to the species $S$. dysenteriae, the type species of the genus Shigella. Although subphenon A6 exhibits an overall similarity of only $86 \%$ to subphenon A5 and a similar similarity to subphenon A3 (Fig. 1), the overlap statistics (Table 6) indicate that subphenon A6 is not a robust cluster. It is of interest that the subgroups discernible within subphenons A5 and A6 correspond to different serotypes (Fig. 1). The study of Goullet (1980) showed that strains of $S$. dysenteriae serotypes 1, 2 and 4 constitute different esterase zymotypes. In particular, the electrophoretic mobilities of the esterases of $S$. dysenteriae serotype 1 strains were markedly different from those of the other $S$. dysenteriae strains studied.

Mannitol negative strains of $S$. boydii serotype 15 appear to be closely related to $S$. dysenteriae serotype 2 strains and our results suggest they should be included within $S$. dysenteriae. Similarly, the clustering of the mannitol negative variant of $S$. flexneri serotype 4a (strain E61), together with its biochemical characteristics noted earlier, indicate that this strain is not merely a variant of $S$. flexneri serotype 4 a which has lost the ability to produce acid from mannitol, but is probably a serotype of $S$. dysenteriae. However, further work is necessary to confirm this and to investigate the systematic position of the mannitol fermenting strains of $S$. flexneri serotype $4 \mathrm{a}$. It is interesting that all the strains received as $S$. flexner $i$ which clustered outside subphenon A3 (S. flexneri, Fig. 1) are of the serotypes and varieties cited by Reavis \& Ewing (1958) as consistently negative for mannitol fermentation.

Our results do not support the exclusion of strains of $S$. dysenteriae provisional serotype 200053 from the genus Shigella (Edwards \& Ewing, 1972). These strains are phenotypically $S$. dysenteriae (Fig. 1). The characteristics of the species $S$. dysenteriae are depicted in Tables 2 and 3.

Subphenon A3 corresponds to the species $S$. flexneri. Only strains of $S$. flexneri serotypes 1 to 5 cluster here. Shigella flexneri serotype 6 strains do not. This is in accord with the findings of many workers that $S$. flexneri serotype 6 strains differ from other strains of the species in their biochemical reactions. They are known to differ in their phage and colicin sensitivity patterns, their lipopolysaccharide structures, in the gene loci determining their antigens and in their esterases (Timakov et al., 1972; Simmons, 1971; Katzenellenbogen et al., 1976; Goullet, 1980). Various workers have suggested the removal of strains designated $S$. flexneri serotype 6 from the species S. flexneri (Timakov et al., 1972; Petrovskaya \& Bondarenko, 1977; Slopek \& Mulczyk, 1967; Gekker et al., 1965; Simmons, 1971; Goullet, 1980). Our findings support this suggestion. The taxonomic position of the $S$. flexneri serotype 6 strains is however difficult to ascertain as the strains examined by us do not cluster within one taxon (Fig. 1).

Petrovskaya \& Bondarenko (1977) suggested that S. flexneri serotype 6 strains should be considered as a biovar of $S$. boydii and this is supported by the work of Goullet (1980) which showed that the esterases of $S$. flexneri serotype 6 strains examined by him were identical to those from strains of $S$. boydii serotypes 2 and 4 . The clustering of three of the $S$. flexneri serotype 6 strains (E88, E92 and E93) in our study supports this proposal, particularly as one of the strains, E88, is most closely related to strains of $S$. boydii serotypes 2 and 4 (strains E18 and E22). Slopek \& Mulczyk (1967) proposed that $S$. flexneri serotype 6 strains should be considered as a new species in the genus Shigella. The nucleus of such a taxon could be represented by subphenon A7 (Fig. 1). However, the overlap statistics indicate that this grouping has dubious validity as a separate taxon. The clustering of the $S$. flexneri 6 aerogenic Newcastle variety strain (E90) is more consistent with this strain being a serotype of $S$. dysenteriae (Fig. 1). Strains designated $S$. flexneri serotype 6 require further study before any recommendation can be made about their taxonomic status. It appears that although they are serologically homogeneous they are biochemically diverse.

The apparent relationship of $S$. boydii serotype 9 strains to the species $S$. flexneri (Fig. 1) also 
Table 6. Overlap results calculated for chosen cluster pairs

$\begin{array}{lcc}\text { Pair of clusters } & \begin{array}{c}\text { Observed overlap, } \\ V_{(G)}(\%)\end{array} & \begin{array}{c}\text { Probability level }(P) \\ \text { at which the overlap }<5 \%\end{array} \\ \text { A1 and A2 } & 0.5 & P<0.90 \\ \text { A1 and A6 } & 1.4 \times 10^{-4} & P>0.99 \\ \text { A1 and A8 } & 4.8 \times 10^{-3} & P>0.99 \\ \text { A2 and A8 } & 2.15 & P<0.90 \\ \text { A3 and A4 } & 0.4 & P>0.99 \\ \text { A3 and A5 } & 0.34 & P>0.99 \\ \text { A3 and A7 } & 4.1 & P<0.90 \\ \text { A4 and A5 } & 0.27 & P>0.99 \\ \text { A4 and A6 } & 2.4 & P<0.90 \\ \text { A4 and A7 } & 6.1 & \dagger<0.90 \\ \text { A5 and A6 } & 2.9 & P>0.99 \\ \text { D1 and D2 } & 7.0 \times 10^{-4} & P>0.99 \\ \text { D1 and D3 } & 6.7 \times 10^{-11} & P>0.99 \\ \text { D2 and D3 } & 1.0 \times 10^{-21} & \dagger \\ \text { D and E } & 0.6 & \end{array}$

${ }^{*} P<0.90$ means that the overlap between the pair of clusters is not significantly less than $5 \%$ at the 0.90 level of significance; $P>0.99$ means that the overlap is significantly greater than $5 \%$ at the 0.99 level of significance. $\dagger t$ test unreliable due to inequality of cluster sizes.

needs further investigation. In the study of Goullet (1980), S. boydii serotype 9 strains constituted a distinct zymotype within the species $S$. boydii, but their esterases were not identical with those of $S$. flexneri serotypes 1 to 5 .

The species $S$. boydii (subphenon A4, Fig. 1) is quite distinct and can be distinguished from members of the species $S$. flexneri (subphenon A3, Fig. 1) on the basis of biochemical and cultural characteristics (see Table 3). This is contrary to the views of workers who have claimed that these two species can be distinguished only by the use of serological methods (Cowan, $1974 a$ ).

The clustering of the 'enterobacterium Sachs' Type 12' strain (E112) within the S. boydii cluster supports the suggestion of Carpenter (1961) and Szturm-Rubinsten et al. (1962), that such strains be regarded as biochemical variants of $S$. boydii serotype 14 and is in agreement with the view of Regina et al. (1981) that Sachs' 'Enterobacterium A12' is an aerogenic variant of Shigella boydii 14.

The clustering of certain strains of $S$. dysenteriae with the species $S$. boydii was unexpected. However, only certain serotypes of $S$. dysenteriae cluster here; all the strains of serotypes $3,5,9$, 10 and provisional serotype 3873-50, but only one strain of serotype 6 (see Fig. 1). This again indicates a close correlation between the serotypes of strains of $S$. dysenteriae and their biochemical and cultural characteristics. Further work is required to confirm the apparent relationships of these strains of $S$. dysenteriae to the species $S$. boydii. As subphenons A4 and A5 (Fig. 1) show little overlap (Table 6), it appears that the serotypes of $S$. dysenteriae which cluster in subphenon A4 (Fig. 1) are distinct from the $S$. dysenteriae strains represented by subphenons A5 and A6 (Fig. 1) and should be designated as new serotypes of $S$. boydii. The species $S$. boydii would then be described as variable for mannitol fermentation.

Subphenon A1 (Fig. 1) corresponds to the species $S$. sonnei. Only one strain not received as $S$. sonnei clusters here (strain E126, E. dispar). The clustering of the newly isolated $S$. sonnei strains into a subgrouping is of particular interest. Such a subgrouping within the species cluster was formed by clinical isolates of Serratia marcescens in the study of Grimont \& Dulong de Rosnay (1972). These strains were found to be multiply resistant to antibiotics and to contain $R$ plasmids. In our study multiple antibiotic resistance (indicating that $\mathbf{R}$ plasmids could be present) was seen in only certain of the 'clinical' S. sonnei, suggesting that other characters are responsible for the close association of these strains. These findings are illustrative of a frequently observed phenomenon that strains may display quite different features after they have been repeatedly subcultured, from those shown when they were originally isolated.

The strains which cluster in subphenon A2 (Fig. 1) require more detailed investigation. Only a few strains of serotype 147 (Table 1) were studied. It is therefore not possible to decide whether 
they should be included in the genus Shigella as part of the species $S$. sonnei, or whether they should be left in the species $E$. coli as at present. The result of the overlap statistic analysis (Table 6) indicates that subphenon A2 overlaps with the strains in subphenon A8 - the AlkalescensDispar group (Fig. 1).

Shigella boydii serotype 13 (strain E33) shows little phenotypic similarity to any of the main Shigella clusters. This correlates with the distinctness of the strains of this serotype indicated by the DNA-DNA hybridization studies of Brenner et al. (1973) and suggests that $S$. boydii strains of this serotype may constitute a new species. Further study of these strains is required.

Of the strains received as members of the Alkalescens-Dispar group, those received as ' $E$. alkalescens' together with one strain received as 'E. dispar' and one received as $E$. coli, constitute subphenon A8, while those strains received as ' $E$. dispar' encompass a range of types with different biochemical characteristics (Fig. 1, Tables 3 and 5). Alkalescens-Dispar strains are presently classed as non-motile, biochemical variants of $E$. coli. While the overlap statistics indicate that subphenon $\mathrm{A} 8$ is distinct from subphenon $\mathrm{A} 1$ ( $S$. sonnei), they do not indicate that subphenon $\mathrm{A} 8$ is distinct from phenon $\mathrm{H}(E$. coli). Therefore, although subphenon A8 appears distinct from $E$. coli in Figs 1 and 2, it may not actually be so. When the pattern coefficient was used phenon $\mathrm{H}$ ( $E$. coli) moved into Area 1 which contains all the Shigella strains and those of the Alkalescens-Dispar group. If the strains clustering in subphenon A8 do constitute a distinct group they may represent a new species in either the genus Shigella or the genus Escherichia.

There is no evidence at all to indicate that the genus Providencia is closely related to any of the shigellae. In the genus Providencia (phenon D, Figs 1 and 2) three groupings can be discerned: $P$. stuartii (D3), $P$. alcalifaciens (D1) and an as yet un-named species (subphenon D2). The validity of this new species is supported by the results of the overlap statistics (Table 6) and by the DNADNA hybridization studies of Brenner et al. (1978). The Prot. rettgeri strains clustering in phenon E probably represent yet another species of the genus Providencia as suggested by the molecular studies of Brenner et al. (1978). The overlap statistics indicate that phenons D and E are not separate clusters (Table 6).

The family Enterobacteriaceae is subdivided into far more name bearing taxa than any other bacterial group (see Edwards \& Ewing, 1972; Cowan, 1974a). This situation has arisen largely due to the clinical importance of many of the taxa. On the basis of DNA-DNA hybridization studies the taxa designated the genera Shigella and Escherichia could be combined (Brenner $e t$ al., 1978). However, as noted by Brenner et al. (1978) there is still a need for purely practical purposes to be able to identify a bacterium in a clinical laboratory as $E$. coli or $S$. dysenteriae. Thus, although the Shigella-Escherichia-Alkalescens-Dispar complex may represent a genospecies as defined by Ravin (1963), the taxospecies into which the complex is now subdivided will probably be used in clinical laboratories for a long time, if not always.

The results presented here indicate that it is possible to distinguish phenotypically at least four taxospecies within the genus Shigella viz. S. dysenteriae, S. flexneri, S. boydii and S. sonnei, and to differentiate them from each other and from $E$. coli and strains labelled ' $E$. alkalescens'. However, each of these taxospecies exhibits a variation of phenotypic characters within the cluster, as wide as that which is exhibited between taxospecies. Thus, if identification of an unknown is based on a few characters only, misidentification can result. However, if classification or grouping is based on the results of many tests then the taxospecies can be reasonably well defined on the basis of their overall properties. Such an exercise is of course not practicable in a clinical laboratory but on the basis of the data presented here reproducible characters can be selected to form the basis of a computer-based identification scheme such as that devised by Bascomb et al. (1973). Such a scheme combined with serological data could be a valuable asset to the clinical laboratory.

\section{REFERENCES}

ANDRewes, F. W. \& InMaN, A. C. (1919). A study of the serological races of the Flexner group of dysentery bacilli. Medical Research Committee, Special Report. Series No. 42, London.
BAKER, F. J. (1967). Handbook of Bacteriological Techniques, 2nd edn. London: Butterworths.

Bascomb, S., Lapage, S. P., Willcox, W. R. \& CURTIS, M. A. (1971). Numerical classification of 
the tribe Klebsiellae. Journal of General Microbiology 66, 279-295.

Bascomb, S., Lapage, S. P., Curtis, M. A. \& Willcox, W. R. (1973). Identification of bacteria by computer: identification of reference strains. Journal of General Microbiology 77, 291-315.

Brenner, D. J., Fanning, G. R., Miklos, G. V. \& Steigerwalt, A. G. (1973). Polynucleotide sequence relatedness among Shigella species. International Journal of Systematic Bacteriology 23, 1-7.

Brenner, D. J., Farmer, J. J., FanNing, G. R., Steigerwalt, A. G., Klyken, P., Wathen, H. G., Hickman, F. W. \& Ewing, W. H. (1978). DNA relatedness of Proteus and Providencia species. International Journal of Systematic Bacteriology 28, 269282.

CARPENTER, K. P. (1961). The relationship of the Enterobacterium A12 (Sachs) to Shigella boydii 14 . Journal of General Microbiology 26, 535-542.

Carpenter, K. P. (1974). Genus Shigella. In Bergey's Manual of Determinative Bacteriology, 8th edn. Edited by R. E. Buchanan \& N. E. Gibbons. Baltimore: Williams \& Wilkins Co.

Catalogue of the National Collection of Type Cultures (1972). London: HMSO.

Cowan, S. T. (1974a). In Bergey's Manual of Determinative Bacteriology, 8th edn. Edited by R. E. Buchanan \& N. E. Gibbons. Baltimore: Williams \& Wilkins Co.

Cowan, S. T. (1974b). Cowan and Steel's Manual for the Identification of Medical Bacteria, 2nd edn. Cambridge: Cambridge University Press.

CraIgIE, J. (1931). Studies on the serological reactions of the flagella of $B$. typhosus. Journal of Immunology 21, 417.

DE ASSIS, A. (1948). Shigella guanabara tipo sorológica destacado do grupo do B , ceylonensis-dispar. Hospital Rio de Janeiro 33, 505-518.

EDWARDS, P. R. \& EWING, W. H. (1972). Identification of Enterobacteriaceae. Minneapolis : Burgess Publishing Co.

EwING, W. H. (1949). Shigella nomenclature. Journal of Bacteriology 57, 633-638.

EwING, W. H. (1963). An outline of nomenclature for the family Enterobacteriaceae. International Bulletin of Bacteriological Nomenclature and Taxonomy 13, 95-110.

EWING, W. H. \& Kauffman, F. (1950). A new coli Oantigen group. United States Public Health Service Public Health Report 65, 1341-1343.

Ewing, W. H., Reavis, R. W. \& Davis, B. R. (1958). Provisional Shigella serotypes. Canadian Journal of Microbiology 4, 89-107.

Feltham, R. K. A., Power, A. K., Pell, P. A. \& SNEATH, P. H. A. (1978). A simple method for storage of bacteria at $-76^{\circ} \mathrm{C}$. Journal of Applied Bacteriology 44, 313-316.

GeKkeR, V. D., Ravitch-Birger, E. D. \& Belaya, J. A. (1965). The position of Newcastle bacteria in the classification of the shigellae. International Bulletin of Bacteriological Nomenclature and Taxonomy 15 , 133-137.

GoulLET, PH. (1980). Esterase electrophoretic pattern relatedness between Shigella species and Escherichia coli. Journal of General Microbiology 117, 493500 .
GOWER, J. C. (1971). A general coefficient of similarity and some of its properties. Biometrics 27, 857-871.

Grimont, P. A. D. \& Dulong de Rosnay, H. L. C. (1972). Numerical study of 60 strains of Serratia. Journal of General Microbiology 72, 259-268.

Henriksen, S. D. (1954). Studies on the Klebsiella group (Kauffmann). II. Biochemical reactions. Acta pathologica et microbiologica scandinavica 34, 259 265.

HowIE, I. S. \& OLD, D. C. (1976). A case of severe bacillary dysentery caused by a gas-producing Shigella boydii type 14 (enterobacterium A12 (Sachs)). Medical Laboratory Sciences 33, 309-315.

HUGH, R. \& LeIFSON, E. (1953). The taxonomic significance of the fermentative versus oxidative metabolism of carbohydrates by various Gram-negative bacteria. Journal of Bacteriology 66, 24-26.

Johnson, R., COLWell, R. R., SAKazaki, R. \& TAMURA, K. (1975). Numerical taxonomy study of the Enterobacteriaceae. International Journal of Systematic Bacteriology 25, 12-37.

Katzenellenbogen, E., Mulczyk, M. \& RomanowsKA, C. (1976). Structural studies on O-specific polysaccharide of $S$. flexneri serotype 6. European Journal of Biochemistry 61, 191-197.

KauffMANN, F. (1954). Enterobacteriaceae, 2nd edn. Copenhagen: Munksgaard.

Kovacs, N. (1956). Identification of Pseudomonas pyocyanea by the oxidase reaction. Nature, London 178 , 703.

MANOLOV, D. G. (1959). A new type of the genus Shigella - 'Shigella 13', Journal of Hygiene, Epidemiology, Microbiology and Immunology 3, 184-190.

Manolov, D. G. \& Trifanova, A. (1962). Works of the Research Institute of Epidemiology and Microbiology, Sofia 8, 1-8.

McKell, J. (1977). A taxonomic study of the ProteusProvidence group with especial reference to the role of plasmids. Ph.D. thesis, University of Leicester.

MCKell, J. \& Jones, D. (1976). A numerical taxonomic study of Proteus-Providence bacteria. Journal of Applied Bacteriology 41, 143-161.

MUMFORD, E. P. \& MOHR, J. L. (1944). Manual on distribution of communicable diseases and their vectors in tropics. American Journal of Tropical Medicine (Supplement) 24, 1-26.

Petrovskaya, V. G. \& Bondarenko, V. M. (1977). Recommended corrections to the classification of Shigella flexneri on a genetic basis. International Journal of Systematic Bacteriology 27, 171-175.

Ravin, A. W. (1963). Experimental approaches to the study of bacterial phylogeny. American Naturalist 97 , 307-318.

REAVIS, R. W. \& EWING, W. H. (1958). Fermentation of raffinose by shigellae. International Bulletin of Bacteriological Nomenclature and Taxonomy 8, 7578.

Regina, M., Toledo, F., Silva, R. M.\& Trabulsi, R. (1981). Sachs' 'Enterobacterium A12' is an aerogenic variant of Shigella boydii 14. International Journal of Systematic Bacteriology 31, 242-244.

REPORT (1951). Nomenclature and classification of the dysentery bacilli. Recommendations of the Shigella Commission (Enterobacteriaceae Subcommittee). International Bulletin of Bacteriological Nomenclature and Taxonomy 1, 150-166. 
REPORT (1953). Minutes of the Judicial Commission on Bacteriological Nomenclature. International Bulletin of Bacteriological Nomenclature and Taxonomy $\mathbf{3}$, 150-151.

REPORT (1954). Report of the Enterobacteriaceae Subcommittee of the Nomenclature Committee of the International Association of Microbiologists. Second Report of the Shigella Commission. International Bulletin of Bacteriological Nomenclature and Taxonomy 4, 47-94.

REPORT (1958). Report of the Enterobacteriaceae Subcommittee of the Nomenclature Committee of the International Association of Microbiological Societies. Supplement to the third report of the Shigella group. International Bulletin of Bacteriological Nomenclature and Taxonomy 8, 93-95.

Rowe, B., Gross, R. J. \& WoOdROOF, D. P. (1977). Proposal to recognize serovar 145/146 (synonyms: 147, Shigella 13, Shigella sofia and Shigella manolovii) as a new E. coli O Group, 0164; International Journal of Systematic Bacteriology 27, 15-18.

Rubinsten, S., Piéchaud, D. \& Kirsche, P. (1950). Shigella saigonensis a propos de treize souches récemment isolées. Annales d'Institut Pasteur 79, 910-913.

SERÉNY, B. (1967). Identification of shigellae on the basis of selective sensitivity. Acta microbiologica Academia scientiarium hungaricae 14, 375-380.

SimmoNs, D. A. R. (1971). Immunochemistry of Shigella flexneri O-antigens: a study of structural and genetic aspects of the biosynthesis of cell-surface antigens. Bacteriological Reviews 35, 117-148.

Skerman, V. B. D., MCGowan, V. \& SNeath, P. H. A. (1980). Approved lists of bacterial names. International Journal of Systematic Bacteriology 30, 225420.

Slopek, S. \& MulczyK, M. (1967). Concerning the classification of $S$. flexneri 6 bacilli. Archivum Immunologiae et Therapiae Experimentalis 15, 600603.

Smith, P. B., HaNCock, G. A. \& RHoden, D. L. (1969). Improved medium for detecting deoxyribonuclease- producing bacteria. Applied Microbiology 18, 991993.

SNEATH, P. H. A. (1968). Vigour and pattern in taxonomy. Journal of General Microbiology 54, 1-11.

SNeATH, P. H. A. (1979). Basic program for significance test for two clusters in euclidean space as measured by their overlap. Computers and Geosciences $\mathbf{5}$, 143-155.

SNEATH, P. H. A. \& Johnson, R. (1972). The influence on numerical taxonomic studies of errors in microbiological tests. Journal of General Microbiology 72, 377-392.

SNEATh, P. H. A. \& Sokal, R. R. (1973). Numerical Taxonomy. San Francisco: Freeman \& Co.

Stevens, M. (1969). Development and use of multiinoculation test methods for a taxonomic study. Journal of Medical Laboratory Technology 26, 253-263.

Szturm-Rubinsten, S., Piéchaud, D. \& Allos, G. (1962). A propos d'une varieté gazogène de Shigella boydii 14. Annales d'Institut Pasteur 103, 303-305.

Tekelieva, R. (1975). Immunochemical studies of the lipopolysaccharides of 'serotype 145-146' (Enterobacteriaceae). Zentralblatt fur Bakteriologie, Parasitenkunde, Infektionskrankheiten und Hygiene (Abteilung I) 231, 92-96.

Timakov, V. D., Petrovskaya, V. G., Bondarenko, V. M. \& K hoMENKo, N. A. (1972). Genetic data concerning Shigella flexneri serotypes 5 and 6 . International Journal of Systematic Bacteriology 22, 149154.

VÉRON, M. (1975). Nutrition and taxonomy of 'Enterobacteriaceae' and related bacteria. I. Technical procedure for auxanograms. Annales de Microbiologie 126, 267-274.

VÉRON, M. \& LE MiNOR, L. (1975). Nutrition and taxonomy of 'Enterobacteriaceae' and related bacteria. II. General results and classification. Annales de Microbiologie 126B, 111-124.

WeIl, A. J., DE Assis, A. \& Slafkovsky, H. (1948). Shigella rio, a new type of Shigella. Journal of Immunology 58, 23-26. 